\title{
Polyunsaturated fatty acids suppress glycolytic and lipogenic genes through the inhibition of ChREBP nuclear protein translocation
}

\author{
Renaud Dentin, ${ }^{1}$ Fadila Benhamed, ${ }^{1}$ Jean-Paul Pégorier, ${ }^{1}$ Fabienne Foufelle, ${ }^{2}$ Benoit Viollet, ${ }^{3}$ \\ Sophie Vaulont, ${ }^{3}$ Jean Girard, ${ }^{1}$ and Catherine Postic ${ }^{1}$

\begin{abstract}
1Département d'Endocrinologie, Institut Cochin, INSERM U567 CNRS UMR8104, Université René Descartes, Paris, France. 2Unité INSERM U671, Centre de Recherches Biomédicales des Cordeliers, Université Paris VI, Paris, France. ${ }^{3}$ Département Génétique, Développement et Pathologie Moléculaire, Institut Cochin, INSERM U567 CNRS UMR8104, Université René Descartes, Paris, France.
\end{abstract}

\begin{abstract}
Dietary polyunsaturated fatty acids (PUFAs) are potent inhibitors of hepatic glycolysis and lipogenesis. Recently, carbohydrate-responsive element-binding protein (ChREBP) was implicated in the regulation by glucose of glycolytic and lipogenic genes, including those encoding L-pyruvate kinase (L-PK) and fatty acid synthase (FAS). The aim of our study was to assess the role of ChREBP in the control of L-PK and FAS gene expression by PUFAs. We demonstrated in mice, both in vivo and in vitro, that PUFAs [linoleate (C18:2), eicosapentanoic acid (C20:5), and docosahexaenoic acid (C22:6)] suppressed ChREBP activity by increasing ChREBP mRNA decay and by altering ChREBP translocation from the cytosol to the nucleus, independently of an activation of the AMP-activated protein kinase, previously shown to regulate ChREBP activity. In contrast, saturated [stearate (C18)] and monounsaturated fatty acids [oleate (C18:1)] had no effect. Since glucose metabolism via the pentose phosphate pathway is determinant for ChREBP nuclear translocation, the decrease in xylulose 5-phosphate concentrations caused by a PUFA diet favors a PUFA-mediated inhibition of ChREBP translocation. In addition, overexpression of a constitutive nuclear ChREBP isoform in cultured hepatocytes significantly reduced the PUFA inhibition of both L-PK and FAS gene expression. Our results demonstrate that the suppressive effect of PUFAs on these genes is primarily caused by an alteration of ChREBP nuclear translocation. In conclusion, we describe a novel mechanism to explain the inhibitory effect of PUFAs on the genes encoding L-PK and FAS and demonstrate that ChREBP is a pivotal transcription factor responsible for coordinating the PUFA suppression of glycolytic and lipogenic genes.
\end{abstract}

\section{Introduction}

Polyunsaturated fatty acids (PUFAs) are potent inhibitors of hepatic glycolysis and de novo lipogenesis, through the inhibition of genes involved in glucose utilization and lipid synthesis, including L-pyruvate kinase (L-PK), fatty acid synthase (FAS), and acetyl-CoA carboxylase (ACC). By regulating this pathway, PUFAs promote a shift from fatty acid synthesis and storage to oxidation (1). With the identification of the transcription factor sterol regulatory element-binding protein-1c (SREBP-1c), the molecular mechanism responsible for the PUFA inhibition of lipogenic genes has made important progress. Indeed, PUFAs inhibit SREBP-1 gene transcription (2), enhance SREBP-1c mRNA turnover (3), and interfere

Nonstandard abbreviations used: ACC, acetyl-CoA carboxylase; Ad-SREBP-1c, recombinant adenovirus expressing SREBP-1c; AICAR, 5-aminoimidazole-4carboxamide-1- $\beta$-D-ribofuranosyl; AMPK, AMP-activated protein kinase; ChoRE, carbohydrate-responsive element; ChREBP, carbohydrate-responsive element-binding protein; DHA, docosahexaenoic acid; dm ChREBP, double mutant ChREBP; EPA, eicosapentanoic acid; FAS, fatty acid synthase; GK, glucokinase; G6P, glucose 6-phosphate; G6PDH, G6P dehydrogenase; $\mathrm{HCHO}$, high-carbohydrate; $\mathrm{LDH}$, lactate dehydrogenase; L-PK, L-pyruvate kinase; PUFA, polyunsaturated fatty acid; RTQ-PCR, real-time quantitative PCR; SREBP-1c, sterol regulatory element-binding protein-1c; X5P, xylulose 5-phosphate.

Conflict of interest: The authors have declared that no conflict of interest exists.

Citation for this article: J. Clin. Invest. 115:2843-2854 (2005).

doi:10.1172/JCI25256. with the proteolytic processing of SREBP-1c protein $(4,5)$. In addition, the fact that overexpression of the nuclear form of SREBP-1c overrides the PUFA suppression of lipogenic gene expression (6, 7) further supports a role for SREBP-1c in mediating the negative effects of PUFAs.

However, the PUFA-mediated suppression of L-PK gene expression cannot be directly attributed to SREBP-1c. Indeed, L-PK expression is not subjected to SREBP-1c regulation (8), and its promoter does not contain a sterol regulatory element-binding (SREbinding) site $(6,9)$. Insulin and glucose both augment L-PK gene expression, but it was demonstrated that the role of insulin in this process is to increase glucokinase (GK) levels to stimulate glucose metabolism (10). While increased glucose metabolism, possibly through the pentose phosphate pathway $(11,12)$, is important for the induction of hepatic L-PK, PUFAs inhibit its transcription (1). Functional mapping analyses have shown that the PUFA response element of the L-PK promoter is colocalized with the carbohydrate-responsive element (ChoRE) binding site $(13,14)$. However, despite several years of investigation, the identity of the transcription factor(s) involved in mediating the negative effects of PUFA on the L-PK gene remains unclear.

Recently, carbohydrate-responsive element-binding protein 1 (ChREBP) was shown to play a pivotal role in the induction of glycolytic and lipogenic genes by glucose $(15,16)$ by its capacity 

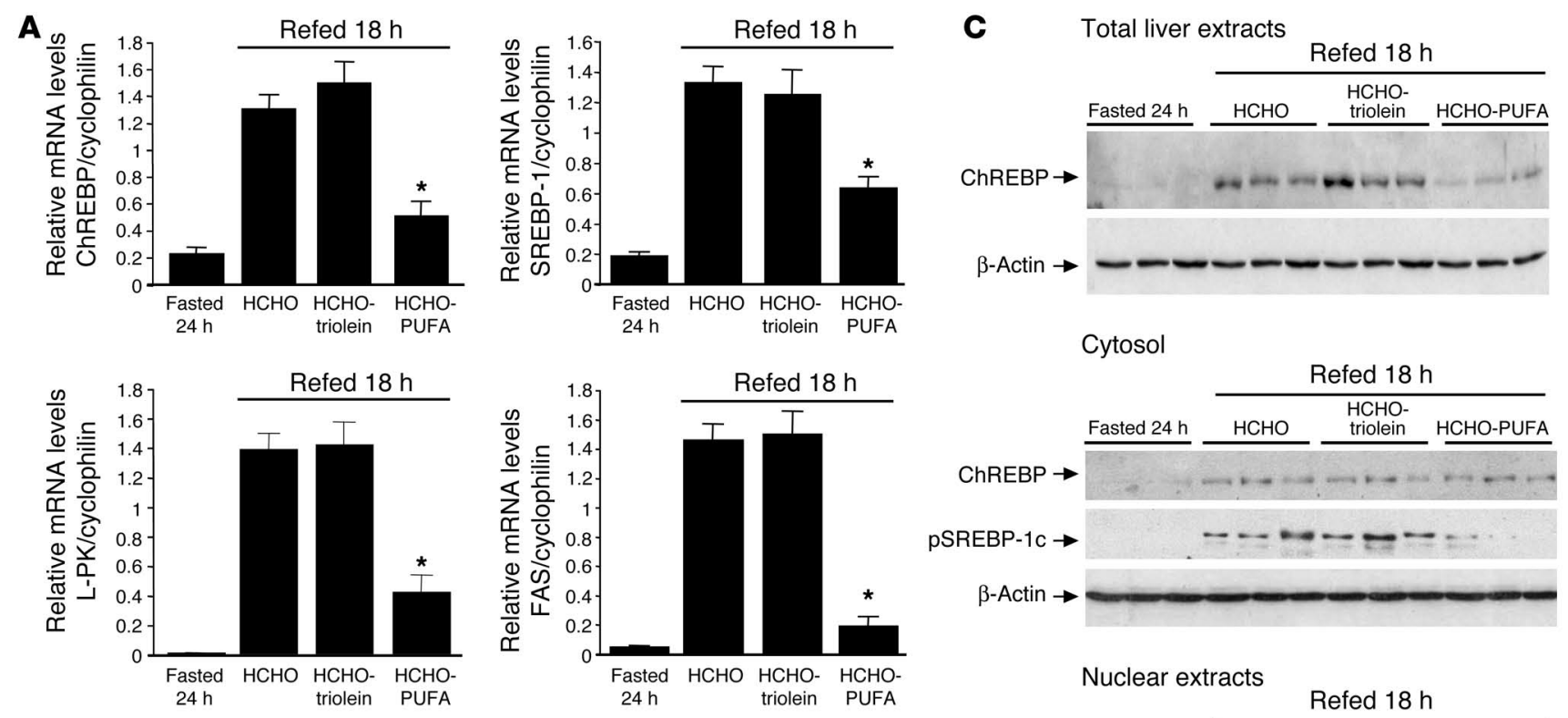

B

Total liver extracts

Refed $18 \mathrm{~h}$
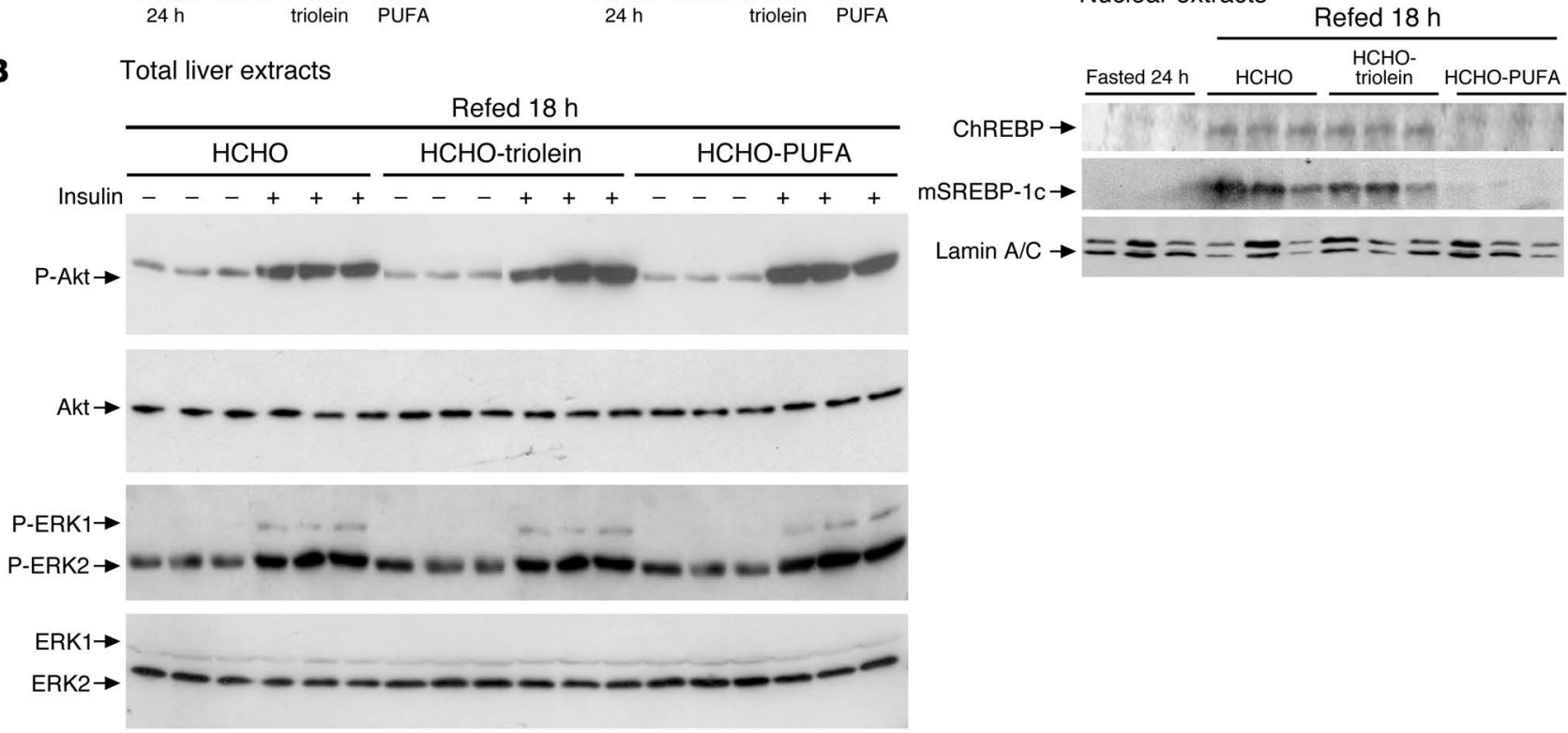

Figure 1

Dietary PUFAs suppress the hepatic abundance of ChREBP mRNA and ChREBP total and nuclear protein content. (A) RTQ-PCR analysis of glycolytic and lipogenic genes from livers of 24 hour-fasted mice and mice refed a HCHO-triolein or HCHO-PUFA diet for 18 hours were performed. Results are the mean $\pm \mathrm{SEM} ; n=6$ /group. *Significantly different from mice refed a HCHO diet for 18 hours $(P<0.005)$. (B) Insulinstimulated liver lysates from 18 hour HCHO-, HCHO-triolein-, and HCHO-PUFA-fed mice blotted with anti-phospho-Akt (P-Akt) and anti-phospho-MAPK antibodies. Blots were then stripped and reprobed for total Akt and MAPK. $n=3 /$ group. (C) Total, cytosolic, and nuclear ChREBP, precursor SREBP-1 (pSREBP-1), and mature SREBP-1 (mSREBP-1) protein, in cytosolic and nuclear extracts from livers of 24 hour-fasted and 18 hour-refed mice on a $\mathrm{HCHO}$ diet supplemented or not with PUFAs. $\beta$-Actin and Lamin A/C antibodies were used as loading controls. A representative Western blot is shown. $n=6 /$ group.

to bind to the ChoRE present in promoters of these target genes (17-19). ChREBP is expressed in liver and is responsive to the nutritional state. The stimulation of ChREBP by glucose occurs at 2 levels. High glucose and insulin concentrations stimulate ChREBP gene expression (15) and also stimulate its translocation from the cytosol to the nucleus, thereby increasing the DNA-binding/transcriptional activity of ChREBP (20). The fact that the DNA-binding activity of ChREBP in nuclear extract of livers from rats fed a high-fat diet is decreased compared with that in rats fed a high-carbohydrate $(\mathrm{HCHO})$ diet suggests that
ChREBP may be intimately involved in fatty acid inhibition of glycolysis and lipogenesis $(18,21)$.

Therefore, we hypothesized that the suppressive effect of PUFAs on glycolytic and lipogenic gene transcription could be mediated, in part, through a decrease in ChREBP gene expression and/or a defect in its nuclear translocation. In this report, we provide evidence for a novel regulatory mechanism of ChREBP activity by PUFAs in liver and demonstrate the direct role of ChREBP in mediating the negative effect of PUFAs on glycolytic and lipogenic genes. 


\section{Results}

Dietary PUFAs reduce the amount of ChREBP $m R N A$ and protein content in vivo. The transcription factor ChREBP is determinant for the induction of glycolytic (L-PK) and lipogenic (FAS, ACC) genes by glucose (15). Since PUFAs suppress glycolytic and lipogenic gene expression in liver, we first examined the possibility that PUFAs may inhibit the expression of ChREBP in vivo (Figure 1). As previously described (15), ChREBP mRNA was induced in liver of fasted mice refed 18 hours with a HCHO diet (Figure 1A). A similar induction was observed when mice were refed with a monounsaturated fatty acid-enriched (i.e., triolein-enriched) diet (HCHO-triolein). In contrast, hepatic levels of ChREBP mRNA were suppressed by 64\% when the HCHO diet contained PUFAs (HCHO-PUFA) (Figure 1A). In parallel, the expression of SREBP-1c, L-PK, and FAS genes was not affected by monounsaturated fatty acids but was decreased by dietary PUFAs (Figure 1A). The lack of induction of glycolytic and lipogenic genes in livers of HCHO-PUFA-refed mice was not due to a defect in insulin released, since plasma insulin concentrations in both refed groups of mice were not significantly different $(1.81 \pm 0.23 \mathrm{ng} / \mathrm{ml}$ for HCHO-refed mice, $1.72 \pm 0.36$ $\mathrm{ng} / \mathrm{ml}$ for HCHO-triolein-refed mice, and $1.51 \pm 0.27 \mathrm{ng} / \mathrm{ml}$ for HCHO-PUFA-refed mice). Moreover, after insulin stimulation, no difference in the phosphorylation status of Akt or MAPKs (ERK1 and ERK2) was observed in the different groups of mice. Our data demonstrate that the PUFA diet did not alter hepatic insulin signaling under our conditions (Figure 1B).

ChREBP content and localization was analyzed under the same experimental conditions. Total ChREBP content was decreased by $60 \%$ in liver extracts from HCHO-PUFA-fed mice compared with mice fed both $\mathrm{HCHO}$ and HCHO-triolein diets (Figure 1C). To address a potential defect in ChREBP translocation, cytosolic and nuclear ChREBP contents were also measured. Both cytosolic and nuclear ChREBP contents were low in livers of 24 hour-fasted mice and increased to similar levels after both $\mathrm{HCHO}$ and $\mathrm{HCHO}$-triolein feeding (Figure 1C). Surprisingly, while ChREBP content was markedly decreased after HCHO-PUFA diet feeding, no significant reduction in cytosolic levels of ChREBP was observed (Figure 1C). In contrast, the HCHO-PUFA diet totally prevented the increase in the nuclear content of ChREBP (Figure 1C). This result probably reflects the accumulation of ChREBP in the cytosol under conditions of impaired protein translocation (i.e., after an enriched PUFA diet). Together our results indicate that PUFAs regulate the abundance of nuclear ChREBP, presumably through the inhibition of its translocation from the cytosol to the nucleus. In addition, the fact that a decrease in the amount of SREBP-1c protein (Figure 1C) was observed suggests that PUFAs inhibit glycolytic and lipogenic gene expres-

Figure 2 sion probably through the concomitant suppression of nuclear ChREBP and SREBP-1c proteins.

PUFAs counteract the effect of glucose and insulin on ChREBP gene expression in cultured hepatocytes. To examine whether fatty acids acted directly on ChREBP gene expression, primary cultures of hepatocytes were incubated with albumin alone or albumin plus various fatty acids (Figure 2). As previously shown (15), ChREBP gene expression was only induced by high glucose and insulin concentrations (Figure 2A). In agreement with our in vivo data (Figure $1 \mathrm{~A})$, incubating hepatocytes with saturated (stearate) or monounsaturated (oleate) fatty acids had no inhibitory effect on ChREBP gene expression (Figure 2). In contrast, hepatocytes cultured with either linoleic acid [C18:2 (n-6)], eicosapentanoic acid [EPA; C20:5 (n-3)] or docosahexaenoic acid [DHA; C22:6 (n-3)] showed a $65 \%$ suppression of ChREBP mRNA levels (Figure 2A). To determine whether the inhibitory effect of PUFAs on ChREBP gene expression was not due to a potentially cytotoxic effect on hepatocytes, lactate dehydrogenase (LDH) activity was measured (Supplemental Figure 1; supplemental material available online with this article; doi:10.1172/JCI25256DS1). Since LDH is a cytosolic enzyme normally absent from the culture medium, LDH activity release in the medium can be used as an index of cytotoxicity. No significant effect of PUFAs (i.e., linoleate, EPA, or DHA) on LDH leakage was observed whatever the fatty acid concentrations tested (Supple-

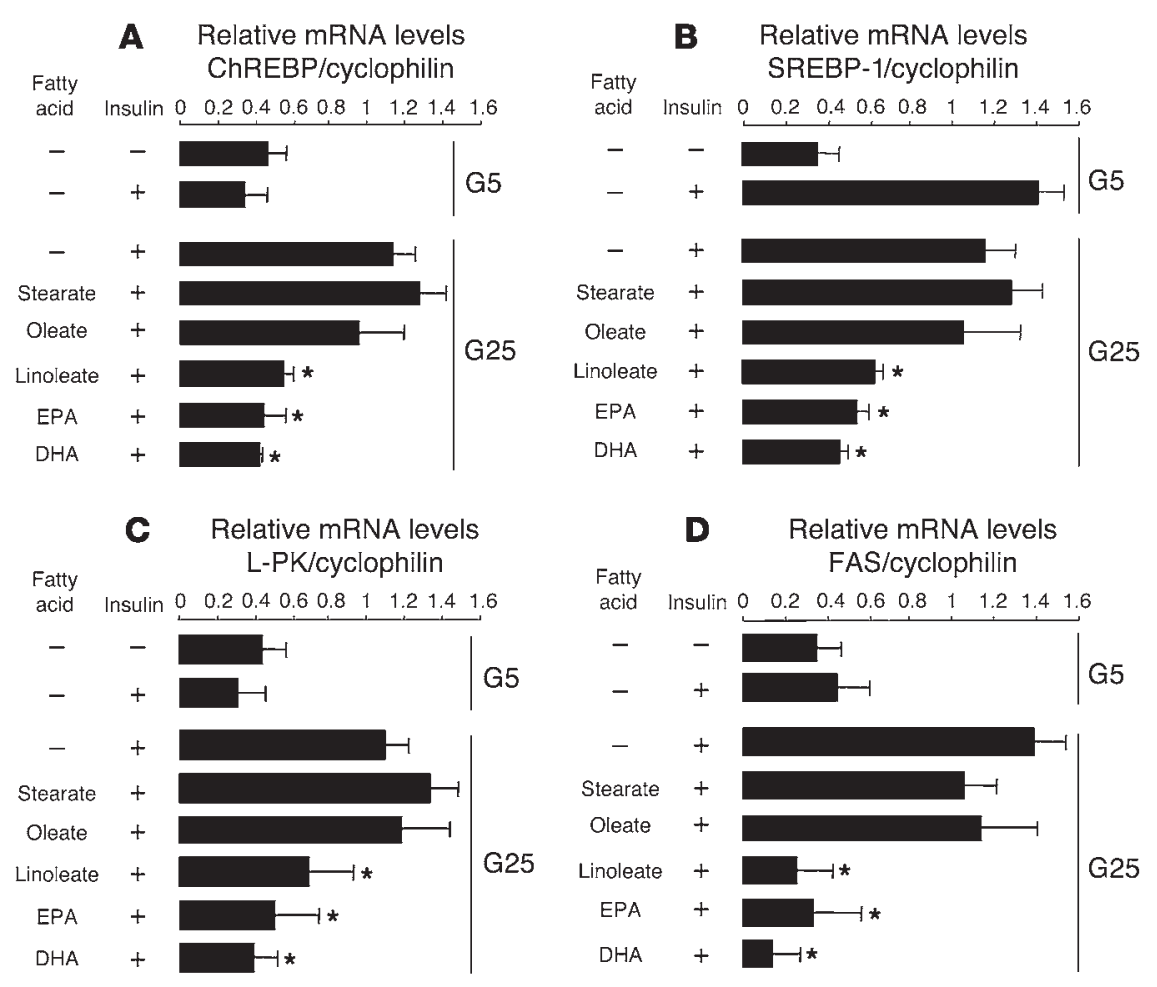

PUFAs inhibit ChREBP gene expression in cultured hepatocytes. After plating, hepatocytes were cultured for 24 hours in the presence of $5 \mathrm{mM}$ glucose. Hepatocytes were then incubated for 24 hours in the presence of 5 or $25 \mathrm{mM}$ glucose (G5 or G25) with $100 \mathrm{nM}$ insulin and 100 $\mathrm{nM}$ dexamethasone in the presence or not of $0.3 \mathrm{mM}$ of albumin-bound stearate (C18), oleate [C18:1(n-9)], linoleate [C18:2 (n-6)], EPA [C20:5 (n-3)], or DHA [C22:6 (n-3)]. ChREBP (A), SREBP-1 (B), L-PK (C), and FAS (D) gene expression were measured by RTQ-PCR. Results are mean \pm SEM of values obtained from 3 to 8 independent cultures. *Significantly different from $25 \mathrm{mM}$ glucose plus insulin $(P<0.05)$. 

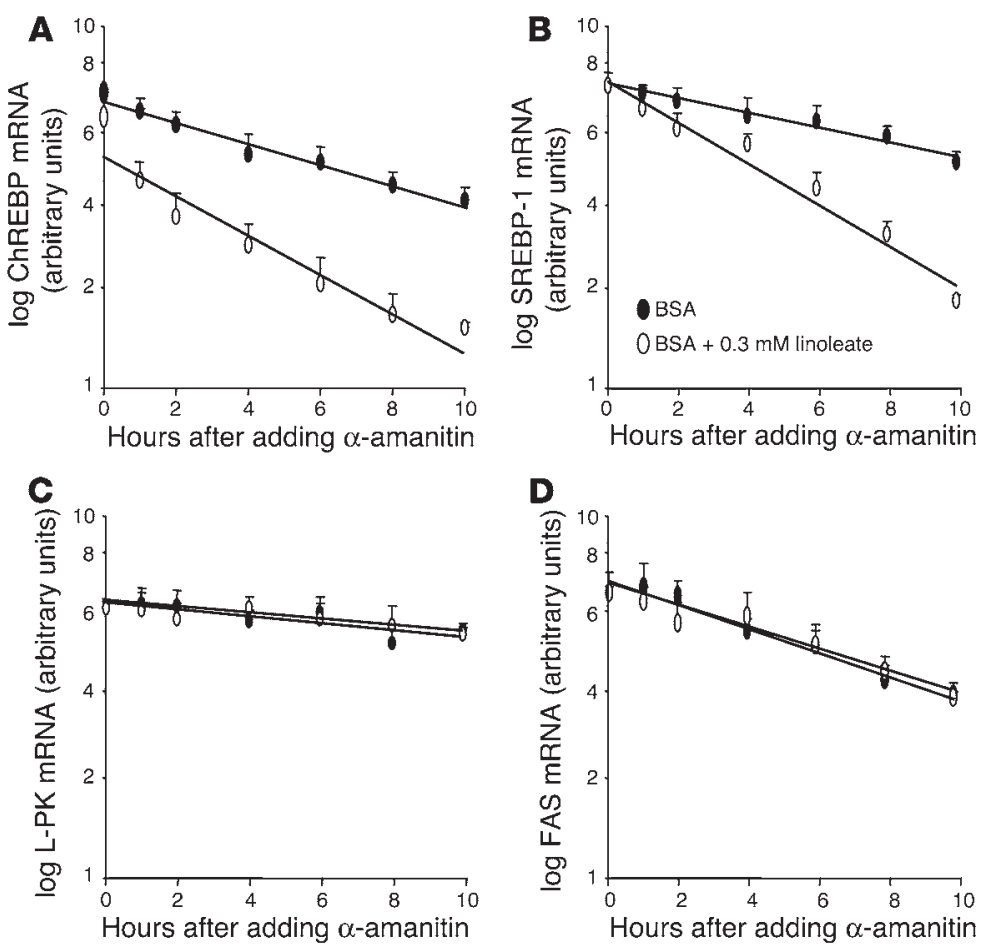

\section{Figure 3}

PUFAs accelerate ChREBP mRNA decay in cultured hepatocytes. After plating, hepatocytes were cultured for 48 hours in the presence of $25 \mathrm{mM}$ glucose and $100 \mathrm{nM}$ insulin. Hepatocytes were then treated with $0.3 \mathrm{mM}$ albumin-bound linoleate (open symbols) or albumin alone (filled symbols) for 2 hours prior to the addition of the transcription inhibitor $\alpha$-amanitin (15 $\mu \mathrm{M}$ final). The abundance of ChREBP (A), SREBP-1 (B), L-PK (C) and FAS (D) mRNA was determined by RTQ-PCR. Results are the mean \pm SEM of values obtained from 3 independent cultures.

transcription (20). To determine whether the PUFAmediated inhibition in ChREBP gene expression was correlated to a decrease in either cytosolic or nuclear ChREBP content, Western blot analysis was performed using protein extracts from hepatocytes cultured in the presence of $25 \mathrm{mM}$ glucose plus $100 \mathrm{nM}$ insulin and treated or not with $0.3 \mathrm{mM}$ linoleate for 24 hours (Figure 4A). Incubation of hepatocytes with glucose and insulin led to a 4.5 -fold increase in ChREBP content in the cytosol, leading to its translocation to the nucleus (Figure 4A). In contrast, after linoleate treatment, although the cytosolic form of ChREBP was increased by insulin and glucose, its translocation from the cytosol to the nucleus was totally prevented (Figure 4A). Under the same experimental conditions, linoleate also

mental Figure 1). Therefore, under our conditions (fatty acids used at $0.3 \mathrm{mM}$ ), the specific inhibitory role of PUFAs on ChREBP gene expression was not due to a cytotoxic effect. Finally, the decrease in ChREBP, SREBP-1c, L-PK, and FAS gene expression, elicited by linoleate, EPA, or DHA, followed a similar pattern (Figure 2, A-D).

Linoleate accelerates ChREBP $m R N A$ decay in cultured hepatocytes. The influence of fatty acids on ChREBP mRNA half-life was examined by pretreating cultured hepatocytes for 2 hours with albumin-bound linoleate or albumin alone after a 48-hour incubation period with high glucose and insulin concentrations to induce ChREBP and SREBP-1c gene expression. Subsequently, $\alpha$-amanitin was added to inhibit gene transcription (Figure 3 ). Under these conditions, linoleate accelerated the rate of ChREBP mRNA decay in cultured hepatocytes (Figure 3A). Regression analysis employing all measurements from 0 to 10 hours indicated that linoleate significantly shortened the half-life of ChREBP mRNA from $13.0 \pm 1.2$ hours to $6.4 \pm 0.8$ hours $(n=3: P<0.05)$. In contrast, neither stearate nor oleate changed ChREBP mRNA decay (data not shown). As previously shown (3), linoleate also accelerated the rate of SREBP- $1 \mathrm{c}$ mRNA decay (from $15.0 \pm 1.0$ hours to $7.3 \pm 1.0$ hours) (Figure $3 \mathrm{~B}$ ) but not that of L-PK and FAS mRNA (Figure 3, C and D).

In order to determine whether the PUFA enhancement of ChREBP mRNA decay involved a short-half-life regulatory protein, the influence of linoleate on ChREBP mRNA decay was examined in the presence of the translational inhibitor cycloheximide (Supplemental Figure 2). Blocking mRNA translation completely eliminated the PUFA-dependent increase in ChREBP mRNA decay, suggesting that the decay process of ChREBP mRNA requires the synthesis of a rapid-turnover protein.

PUFAs suppress the nuclear translocation of ChREBP in cultured hepatocytes. Nuclear translocation of ChREBP is one of the important processes in the glucose activation of L-PK or FAS gene significantly reduced the content of both precursor and mature SREBP-1 protein (Supplemental Figure 3).

To further investigate the effect of various fatty acids on the subcellular localization of ChREBP, a GFP-fused ChREBP was transfected in cultured hepatocytes (Figure 4B). In agreement with previous studies (20), the GFP-fused ChREBP was mainly detected in the cytosol of hepatocytes at low glucose concentrations with or without insulin and migrated into the nucleus when hepatocytes were cultured at high glucose and insulin concentrations (Figure 4B). The GFP-fused ChREBP also showed appropriate nuclear translocation when hepatocytes were cultured at high glucose and insulin concentrations and in the presence of either saturated (stearate) or monounsaturated (oleate) fatty acids (Figure 4B). In contrast, PUFAs (linoleate, EPA, and DHA) markedly inhibited nuclear translocation of the GFP-fused ChREBP (Figure 4B), demonstrating that alteration in ChREBP translocation into nucleus was specific to PUFAs.

The alteration in ChREBP translocation is not linked to an activation of $A M P K$ by PUFAs in vitro and in vivo. It was proposed that the fatty acid inhibition of glucose-induced L-PK gene transcription resulted from AMPK phosphorylation of ChREBP at Ser568, which then inactivated its DNA-binding activity (21). The activation of AMPK would result from the increased AMP concentrations generated by fatty acid activation in acyl-coA (21). We therefore determined whether the lack of nuclear ChREBP translocation in the presence of PUFAs could be associated with the activation of AMPK. The AMPK activator 5-aminoimidazole-4-carboxamide-1- $\beta$-D-ribofuranosyl (AICAR) used at $500 \mu \mathrm{M}$ increased the phosphorylated active form of AMPK in cultured hepatocytes at 1, 2, 6, and 10 hours (Figure 5A, upper panel), resulting, as previously shown $(22,23)$, in the inhibition of the glucose activation of L-PK and FAS gene transcription (data not shown). Under these conditions, the activation of AMPK by AICAR had no effect on ChREBP translocation to the 


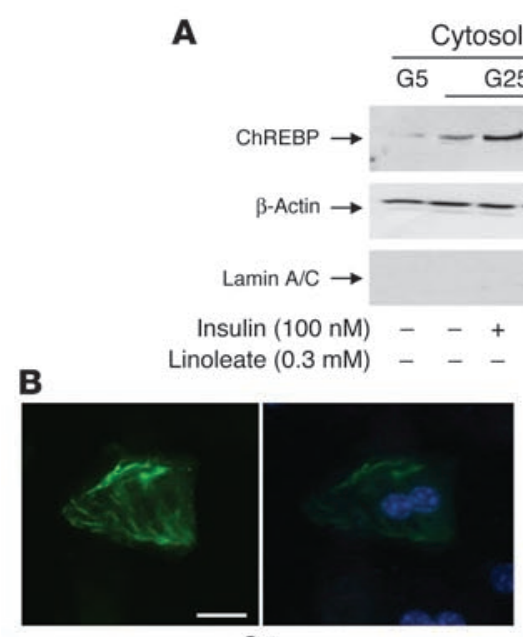

G5

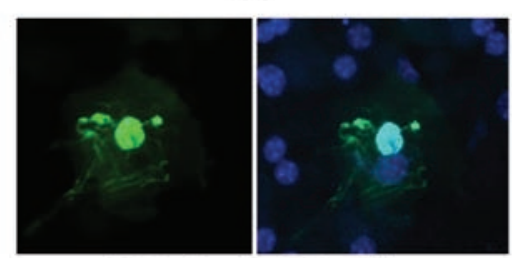

G25 + insulin (100 nM)

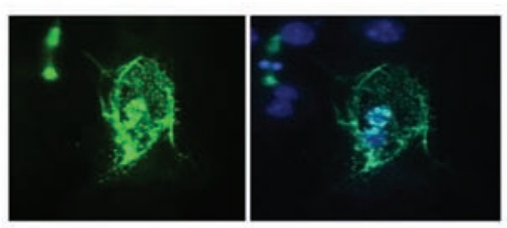

G25 + insulin (100 nM)

+ oleate $(0.3 \mathrm{mM})$

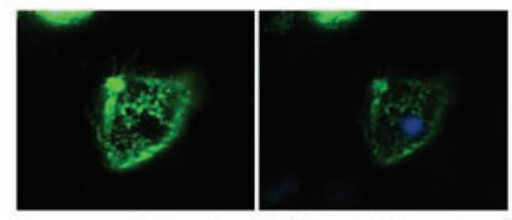

G25 + insulin (100 nM)

+ EPA (0.3 mM)
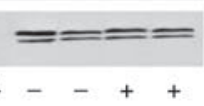

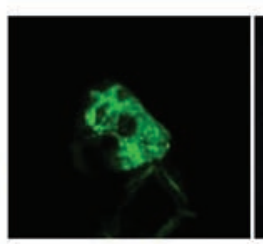

G5 + insulin (100 nM)

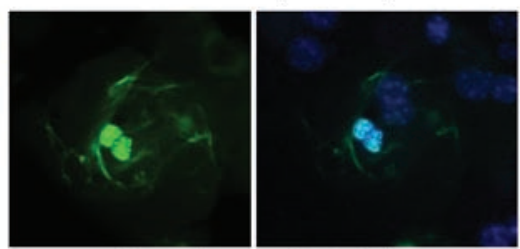

G25 + insulin (100 nM)

+ stearate $(0.3 \mathrm{mM})$

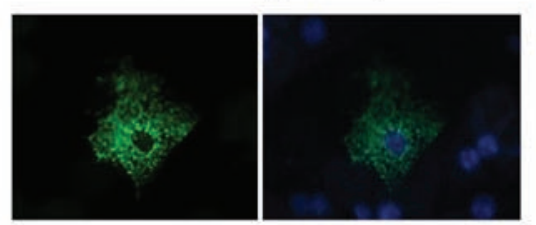

G25 + insulin (100 nM)

+ linoleate $(0.3 \mathrm{mM})$
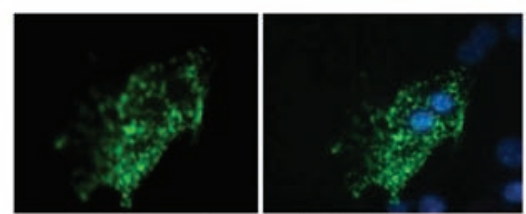

G25 + insulin (100 nM)

$+\mathrm{DHA}(0.3 \mathrm{mM})$

\section{Figure 4}

PUFAs suppress nuclear translocation of ChREBP in cultured hepatocytes. After plating, hepatocytes were cultured for 24 hours in the presence of $5 \mathrm{mM}$ glucose. Hepatocytes were then incubated for 24 hours in the presence of 5 or $25 \mathrm{mM}$ glucose with or without $100 \mathrm{nM}$ insulin and $100 \mathrm{nM}$ dexamethasone containing or not $0.3 \mathrm{mM}$ of albumin-bound linoleate. (A) Cytosolic and nuclear forms of ChREBP were measured. Representative Western blots of 4 independent cultures are shown. (B) Representative images of subcellular localization of GFP-fused ChREBP under $5 \mathrm{mM}$ glucose with or without $100 \mathrm{nM}$ insulin; and 25 $\mathrm{mM}$ glucose plus $100 \mathrm{nM}$ insulin with or without 0.3 $\mathrm{mM}$ of albumin-bound stearate (C18), oleate [C18:1 $(n-9)]$, linoleate [C18:2 (n-6)], EPA [C20:5 (n-3)], or DHA [C22:6 (n-3)]. For each condition, hepatocyte nuclei were specifically stained using DAPI (right panels). Scale bar, $10 \mu \mathrm{M}$.

not affect ChREBP subcellular localization. Indeed, under $\mathrm{HCHO}$ feeding, ChREBP was appropriately translocated into the nucleus of hepatocytes and was still retained in the cytosol under PUFA conditions (Figure 5D). In addition, the inhibition in both L-PK and FAS expression was sustained in livers of AMPK $\alpha 1^{-/-}$and AMPK $\alpha 2^{-/-}$mice in the presence of PUFAs (Figure 5E). Together, our in vitro and in vivo data demonstrate that the effect of PUFAs on ChREBP translocation is not due to an activation of AMPK.

PUFAs reduce GK and glucose 6-phosphate debydrogenase activities both in vivo and in vitro. The present study reports that high glucose and insulin concentrations are required for an efficient translocation of ChREBP into the nucleus (Figure 4A). The regulation of ChREBP nuclear translocation involves the pentose phosphate pathway and particularly xylulose 5-phosphate (X5P), which, by selectively activating protein phosphatase $2 \mathrm{~A}$ (PP2A), was shown to dephosphorylate ChREBP, thereby allowing its translocation into the nucleus (27). In order to determine the molecular mechanisms by which PUFAs interfere with ChREBP translocation, we measured the

nucleus in response to high glucose and insulin concentrations (Figure 5A, lower panel). In hepatocytes cultured in the presence of $0.3 \mathrm{mM}$ linoleate, no activation of AMPK was observed (Figure 5A, upper panel), but ChREBP translocation was inhibited by about $80 \%$ at 2 hours, $65 \%$ at 6 hours, and $55 \%$ at 10 hours (Figure $5 \mathrm{~A}$, lower panel). Similarly, no activation of AMPK was observed in the presence of stearate, oleate, EPA, or DHA (Figure 5B).

To also address the effects of PUFAs on AMPK in vivo, the phosphorylation status of AMPK was measured in liver of 24 hourfasted mice refed for 3 hours on a $\mathrm{HCHO}$ diet containing or not containing PUFAs (Figure 5C). AMPK phosphorylation, which expectedly increased in liver of 24 hour-fasted mice (24), was similarly decreased after both $\mathrm{HCHO}$ and $\mathrm{HCHO}-\mathrm{PUFA}$ feeding (Figure 5C). Finally, to directly address the role of AMPK in the control of ChREBP translocation by PUFAs, a series of experiments in AMPK $\alpha 1^{-/-}$and AMPK $\alpha 2^{-/-}$mice was performed $(25,26)$ (Figure $5 \mathrm{D})$. The lack of either the $\alpha 1$ or $\alpha 2$ subunit of AMPK in mice did activities of GK (the rate-limiting enzyme of glycolysis) and of glucose 6-phosphate (G6P) dehydrogenase (G6PDH; the rate-limiting enzyme of the pentose phosphate pathway) required for the synthesis of X5P from G6P. Refeeding mice with a HCHO diet for 18 hours or culturing hepatocytes in the presence of $25 \mathrm{mM}$ glucose and $100 \mathrm{nM}$ insulin for 24 hours led to a parallel increase in GK protein content and activity (Figure 6, A and B). This elevated GK activity was associated with an increase in G6P concentrations both in vivo and in vitro (Figure 6, $\mathrm{A}$ and $\mathrm{B}$ ). G6PDH activity was also increased both in vivo and in vitro (by 8-and 4-fold, respectively) (Figure 6C). Supplementing the $\mathrm{HCHO}$ diet with triolein (Figure 6A) or culturing hepatocytes in the presence of saturated (stearate) or monounsaturated (oleate) fatty acids had no effect on GK or G6PDH activity (data not shown). In contrast, a PUFA-enriched diet or linoleate decreased GK protein content and activity and consequently G6P concentrations by about $50 \%$ (Figure 6 , A and $\mathrm{B}$ ) as well as the activity of $\mathrm{G} 6 \mathrm{PDH}$ and $\mathrm{X} 5 \mathrm{P}$ concentrations by about $70 \%$ both in vivo and in vitro (Figure $6 \mathrm{C}$ ). Our data demon- 
A Cytosol

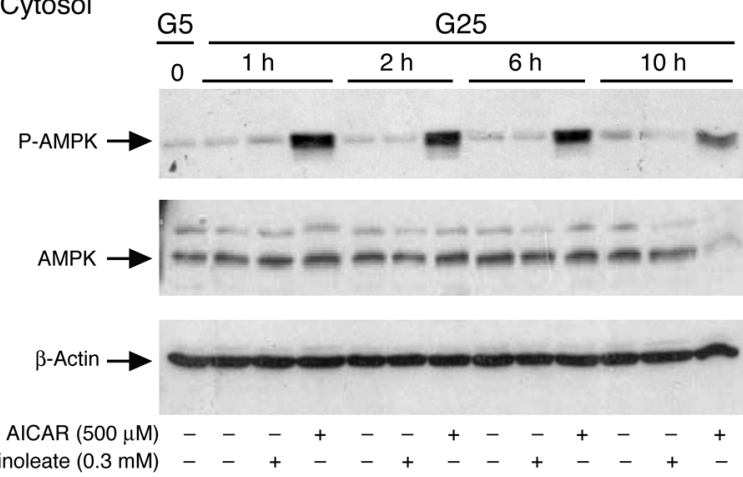

Nuclear extracts

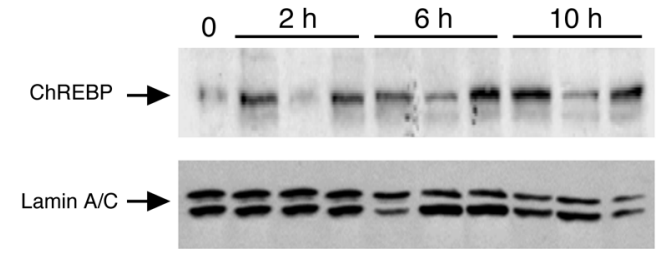

$\operatorname{AICAR}(500 \mu \mathrm{M})-{ }_{-}+-\quad+\quad+-$ Linoleate $(0.3 \mathrm{mM})-{ }_{-}+-\ldots+-\ldots+$

B

Cytosol

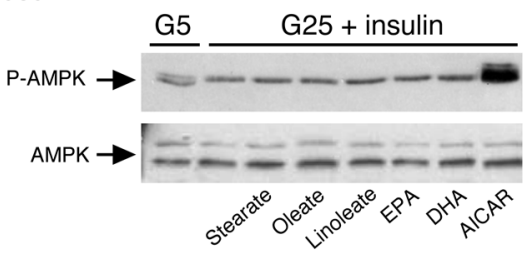

C

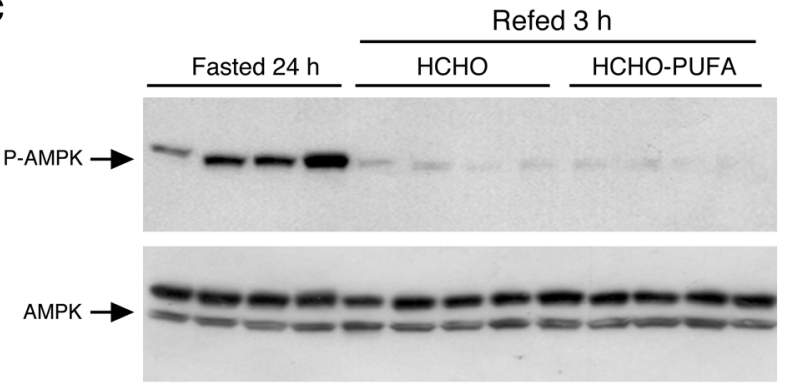

D

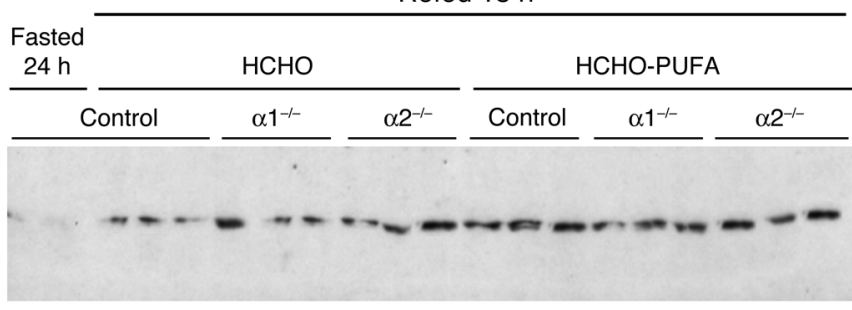

Nuclear extracts

ChREBP -

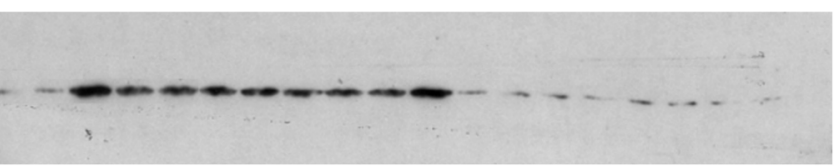

Total liver extracts

AMPK $\alpha 1 \rightarrow$

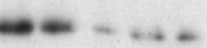

$-\infty-\omega-\infty$

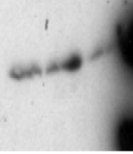

E

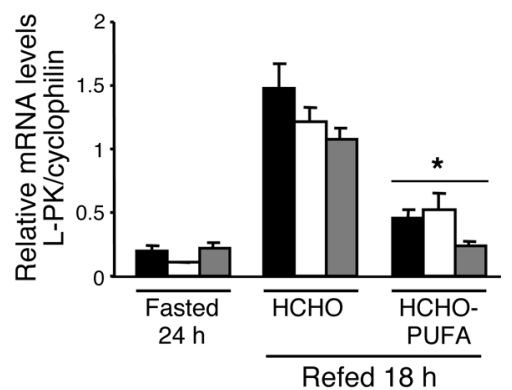

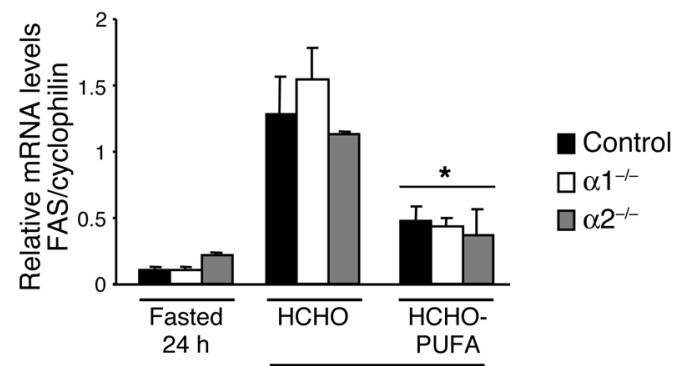

Refed $18 \mathrm{~h}$

Figure 5

Effect of PUFAs and AICAR on AMPK activation and ChREBP localization. In vitro studies: After plating, hepatocytes were cultured for 24 hours in the presence of $5 \mathrm{mM}$ glucose and $100 \mathrm{nM}$ insulin. (A) Hepatocytes were then incubated with $25 \mathrm{mM}$ glucose and $100 \mathrm{nM}$ insulin in the presence or not of $0.3 \mathrm{mM}$ of albumin-bound linoleate or $500 \mu \mathrm{M}$ AICAR. After 1, 2, 6, and 10 hours, cytosolic form of phospho-AMPK and nuclear forms of ChREBP were measured. (B) After a 6-hour incubation period with $25 \mathrm{mM}$ glucose, $100 \mathrm{nM}$ insulin, and $0.3 \mathrm{mM}$ of albumin-bound stearate (C18), oleate [C18:1 (n-9)], linoleate [C18:2 (n-6)], EPA [C20:5 (n-3)], DHA [C22:6 (n-3)], or 500 MM AICAR, the cytosolic form of P-AMPK protein was measured. Representative Western blots of 4 independent cultures are shown. In vivo studies: (C) The phosphorylation status of AMPK was measured in liver extracts from 24 hour-fasted mice refed for 3 hours on a $\mathrm{HCHO}$ or a HCHO-PUFA diet. $n=4 / g$ roup. (D) Cytosolic and nuclear ChREBP content from livers of 24 hour-fasted control and AMPK $\alpha 1^{-/-}$or AMPK $\alpha 2^{-l_{-}}\left(\alpha 1^{-/-}\right.$and $\left.\alpha 2^{-/-}\right)$mice refed 18 hours upon $\mathrm{HCHO}$ diet supplemented or not with PUFAs. A representative Western blot is shown; $n=3 /$ group. (E) RTQ-PCR analysis of L-PK and FAS genes from livers of 24 hour-fasted mice and mice refed 18 hours on a $\mathrm{HCHO}$ or $\mathrm{HCHO}-\mathrm{PUFA}$ diet were performed in control and $\mathrm{AMPK} \alpha 1^{-/-}$or $\mathrm{AMPK} \alpha 2^{-/-}$mice. Results are the mean $\pm \mathrm{SEM} ; n=3$ /group. *Significantly different from mice refed a HCHO diet for 18 hours $(P<0.005)$.

strate that the defect in ChREBP translocation observed in presence of PUFAs (Figure 4A) is linked to a decrease in glucose phosphorylation capacities and to an inhibition of the pentose phosphate pathway, which lead to a decrease in X5P concentrations.
Role of ChREBP in fatty acid suppression of glycolytic and lipogenic gene expression. We have shown that ChREBP acts in synergy with SREBP-1c to induce glycolytic (L-PK) and lipogenic (FAS) gene expression (15). To determine to what extent ChREBP participates, with SREBP-1c, 
A

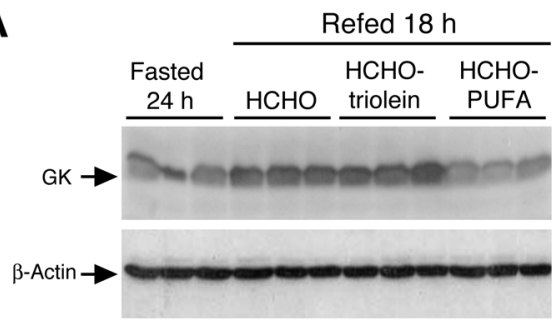

B

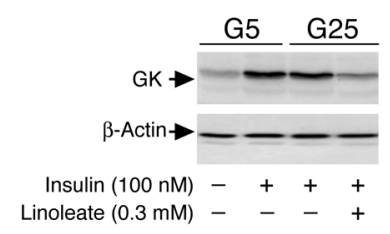

C

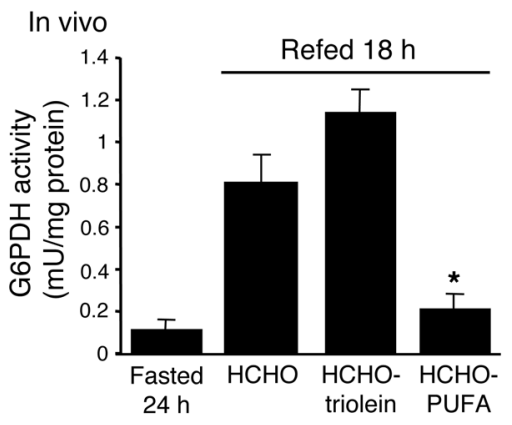

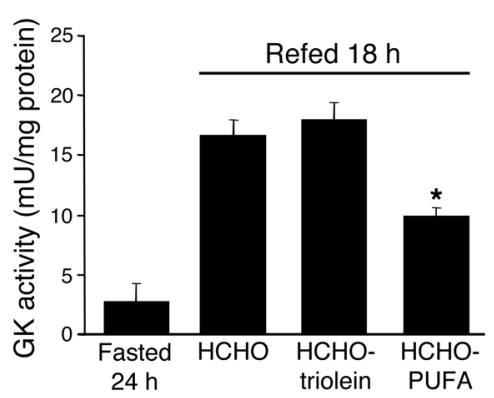
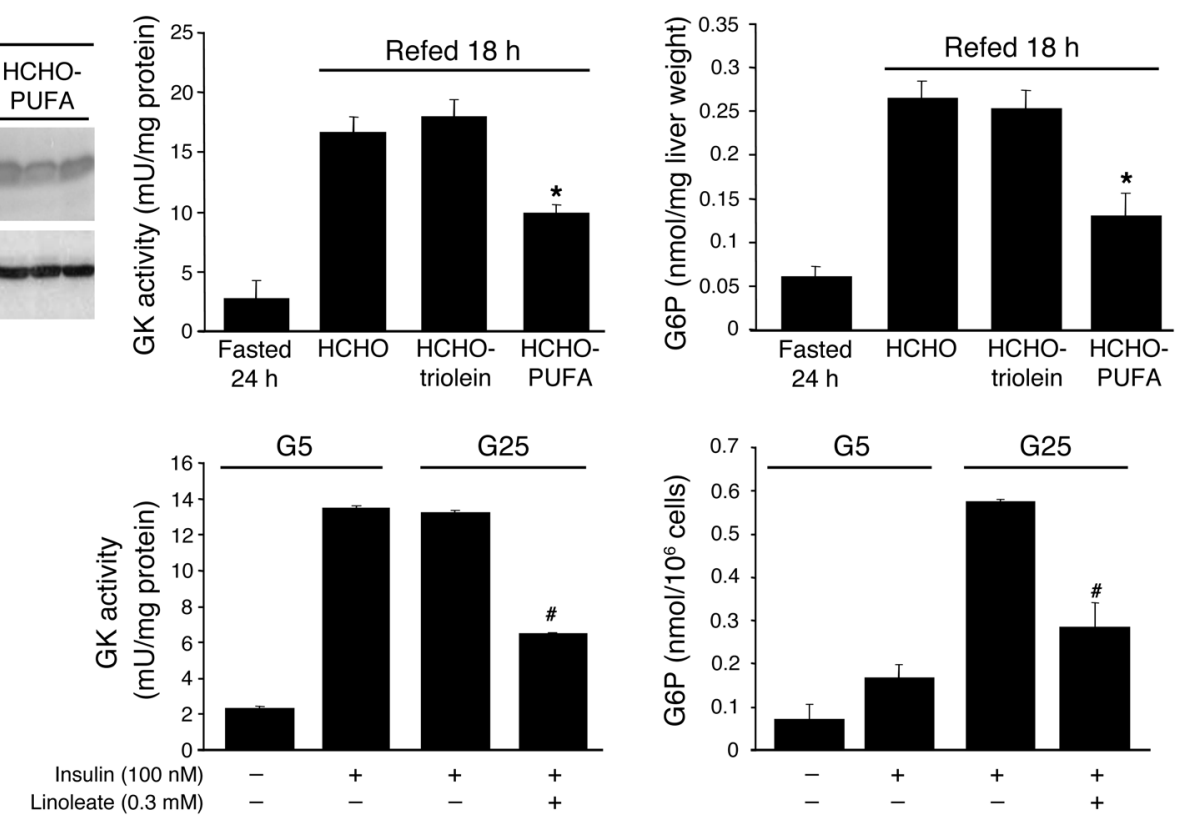
Linoleate $(0.3 \mathrm{mM})$

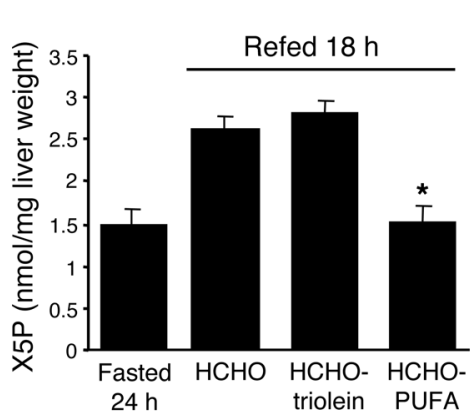

In vitro
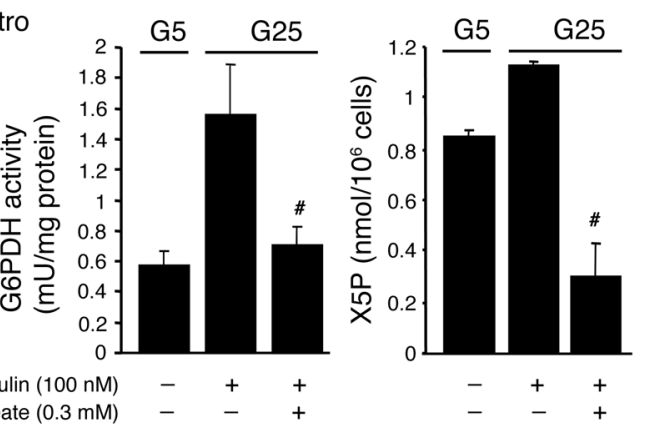

Figure 6

Key steps of glycolysis and pentose phosphate pathway are decreased by PUFAs both in vivo and in vitro. In vivo studies: Mice were fasted for 24 hours and then refed 18 hours on a HCHO-triolein or HCHO-PUFA diet. In vitro studies: After plating, hepatocytes were cultured for 24 hours in the presence of $5 \mathrm{mM}$ glucose. Hepatocytes were then incubated for 24 hours in the presence of 5 or $25 \mathrm{mM}$ glucose with $100 \mathrm{nM}$ insulin in the presence or not of $0.3 \mathrm{mM}$ of albumin-bound linoleate [C18:2 (n-6)]. (A) GK protein content and activity and G6P concentrations in vivo. Results are presented as the mean $\pm \mathrm{SEM} ; n=6$ /group. *Significantly different from mice refed a HCHO diet for 18 hours $(P<0.005)$. (B) GK protein content and activity and G6P concentrations were measured in vitro. Results are mean \pm SEM of values obtained from 4 independent cultures. \#Significantly different from $25 \mathrm{mM}$ glucose plus insulin $(P<0.005)$. (C) G6PDH activity and X5P concentrations in vivo and in vitro. Results are presented as the mean \pm SEM; $n=6$ /group. *Significantly different from mice refed a HCHO diet for 18 hours $(P<0.005)$. \#Significantly different from $25 \mathrm{mM}$ glucose plus insulin $(P<0.005)$.

in mediating the negative effect of PUFAs on hepatic glycolytic and lipogenic gene expression, the transcriptionally active form of SREBP-1c was overexpressed in primary cultures of hepatocytes through the use of an adenovirus in order to override the negative effects of PUFAs (Figure 7, A and B). While SREBP-1c overexpression markedly induced FAS gene expression, it moderately induced the expression of the L-PK gene compared with insulin stimulation conditions (Figure 7A). When SREBP-1c was overexpressed, linoleate no longer affected FAS mRNA levels but still repressed the expression of L-PK by $45 \%$ (Figure 7A). Our results suggest that the absence of ChREBP in the nucleus is likely responsible for the lack of induction of the L-PK in presence of PUFAs (Figure 7B).

To assess the role of ChREBP in the control of L-PK and FAS gene expression, we overexpressed a dephosphorylated mutant form of ChREBP in which amino acids Ser196 and Thr666 were mutated to alanine (double mutant ChREBP [dm ChREBP]), thereby allowing the constitutive expression of the mutant in the nucleus (17). Overexpression of the FLAG-dm ChREBP led to a significant increase in the amount of ChREBP in the nucleus under both low $(5 \mathrm{mM})$ and high glucose $(25 \mathrm{mM})$ concentrations compared with nontransfected conditions (Figure 8B). Furthermore, while linoleate altered the nuclear translocation of endogenous ChREBP, it did not affect that of the transfected $\mathrm{dm}$ ChREBP (Figure 8A). As a result, the constitutive expression of $\mathrm{dm}$ ChREBP in the nucleus completely counteracted the negative effect of linoleate on L-PK gene expression and partially restored $(70 \%)$ the induction of FAS gene expression (Figure 8C). The fact that dm ChREBP partially restored FAS gene expression and that linoleate still repressed the mature form of SREBP-1c (Figure 8A) confirms the role of SREBP-1c in the PUFA-mediated inhibition of lipogenic genes. Our results show, for the first time to our knowledge, the involvement of ChREBP in mediating the negative effects of PUFAs on the L-PK 
A

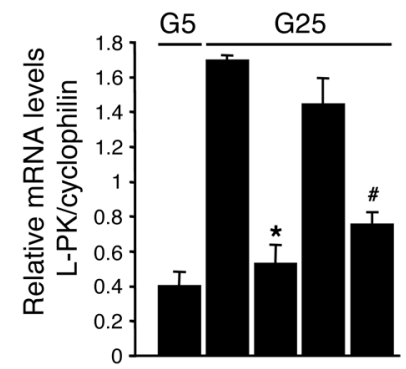

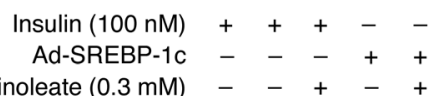

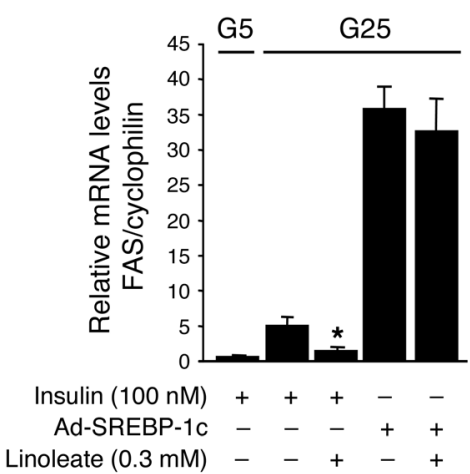

B

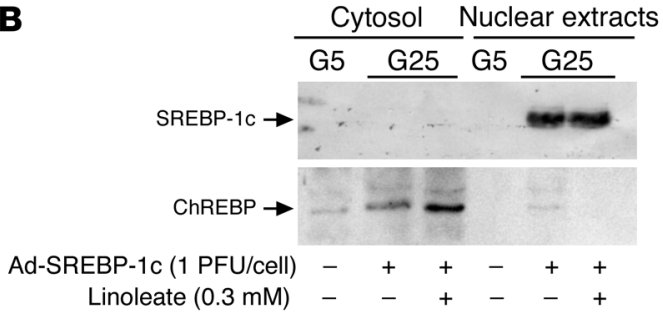

gene and further underline the synergistic role of ChREBP and SREBP-1c in regulating FAS gene expression.

\section{Discussion}

Supplementing a HCHO diet with oils rich in (n-6) and (n-3) PUFAs results in an inhibition of a wide array of glycolytic and lipogenic enzymes including L-PK, FAS, or ACC $(1,28,29)$. Although SREBP-1c was described as a major mediator of the negative effects of PUFAs on lipogenic genes in liver $(4,6,7,28)$, this transcription factor cannot explain by itself the PUFA-mediated suppression of the L-PK gene $(6,8)$. Indeed, the L-PK promoter does not contain SRE-binding sites (6), and its ChoRE weakly binds SREBP-1c $(6,9)$. The recent observation that ChREBP acts in synergy with SREBP-1c to induce glycolytic and lipogenic gene expression (15) and that fatty acids suppress ChREBP gene expression in an adipocyte cell line (30) prompted us to analyze the role of this transcription factor in the PUFA-mediated inhibition of glycolytic and lipogenic genes in liver.

The present study clearly shows that PUFAs [essentially (n-6) and (n-3) fatty acids], but not saturated or monounsaturated fatty acids, downregulate ChREBP gene expression both in vivo and in vitro by accelerating ChREBP mRNA decay. A similar regulation has been described for SREBP-1c (3), but despite the identification of potential destabilizing elements (A-U rich region) in the $3^{\prime}$ untranslated region of both genes (data not shown), the mechanisms by which PUFAs accelerate SREBP-1c and ChREBP mRNA decay remain unclear. However, the fact that cycloheximide completely blocked the ability of PUFAs to accelerate ChREBP mRNA decay suggests that ChREBP mRNA translation is required for mRNA decay and/or that PUFA may modulate the activity of a rapid-turnover protein involved in ChREBP mRNA decay. The possibility that PUFAs may also exert a transcriptional effect on the ChREBP gene is, however, not excluded but would require ChREBP promoter analysis. The fact that the inhibition of ChREBP gene expression was restricted to PUFAs is in agreement with other studies in which only PUFAs are described as potent inhibitors of

\section{Figure 7}

Overexpression of SREBP-1c in cultured hepatocytes overrides the PUFA suppression of FAS but not of L-PK gene expression. After plating, hepatocytes were cultured for 24 hours in the presence of $5 \mathrm{mM}$ glucose. Hepatocytes were then incubated with 5 or $25 \mathrm{mM}$ glucose with the Ad-SREBP-1c at 1 PFU/cell in the presence or not of 0.3 $\mathrm{mM}$ of albumin-bound linoleate. (A) After 24 hours, L-PK and FAS gene expression was analyzed by RTQ-PCR. Results are the mean \pm SEM of values obtained from 4 independent cultures. *Significantly different from conditions with insulin and no linoleate $(P<0.05)$. "Significantly different from conditions with Ad-SREBP-1c and no linoleate. (B) Cytosolic and nuclear forms of ChREBP and mature form of SREBP-1C were measured. A representative Western blot of 4 independent cultures is shown.

glycolysis and lipogenesis in liver $(14,31,32)$ but in contrast with studies by He et al. (30) and Kawaguchi et al. (21) in which saturated and monounsaturated fatty acids were shown to inhibit ChREBP gene expression.

Our study not only demonstrates that PUFAs decrease ChREBP total protein content but also and more importantly that PUFAs alter the mechanism of ChREBP translocation from the cytosol to the nucleus. The shuttling of ChREBP between the cytosol and the nucleus is indeed an important process in its ability to activate target genes in response to glucose (33). ChREBP contains at least 3 phosphorylation sites important for its activation (20). The dephosphorylation of Ser196, located near the nuclear localization signal, requires the activation of glucose metabolism in which X5P, a metabolite of the pentose phosphate pathway, seems necessary for the induction of PP2A, itself required for ChREBP dephosphorylation and entry to the nucleus (27). Therefore, the decrease in both GK (a key enzyme of glycolysis) and G6PDH (the rate-limiting enzyme of the pentose phosphate pathway) activities, leading to a decrease in 2 key metabolites of glucose metabolism (G6P and X5P), favors a PUFA-mediated inhibition of ChREBP translocation. Consistent with the observation that GK gene expression is inhibited by PUFAs (34), our study clearly shows that only PUFAs, but not saturated or monounsaturated fatty acids, inhibit GK activity by decreasing the amount of total GK protein content. Similarly, the PUFA-mediated inhibition of G6PDH observed is in accordance with studies reporting that G6PDH activity, like other lipogenic enzymes, is induced by HCHO feeding (35, 36) and decreased by high-fat diets (37-39). Based on these observations, we conclude that PUFAs, by decreasing rate-limiting enzymatic steps of glycolysis and pentose phosphate pathway, lead to the inhibition of ChREBP translocation into the nucleus.

The mechanism previously described to explain the inhibitory effect of fatty acids on ChREBP function involved the activation of AMPK but not a defect in ChREBP translocation (21). Kawaguchi and coworkers reported that short-, medium-, and long-chain saturated fatty acids activated AMPK in cultured hepatocytes (21). The activation of AMPK, resulting from the increased in AMP concentrations in the cell, led to the phosphorylation of ChREBP on Ser568, which then caused a decrease in ChREBP binding capacities on its ChoRE, leading to the inhibition of L-PK. A concern in interpreting the results of Kawaguchi et al. (21) is that only PUFAs were reported as inhibitors of glycolytic and lipogenic gene expression but not medium- (40) or long-chain saturated and monounsaturated 
A Nuclear extracts

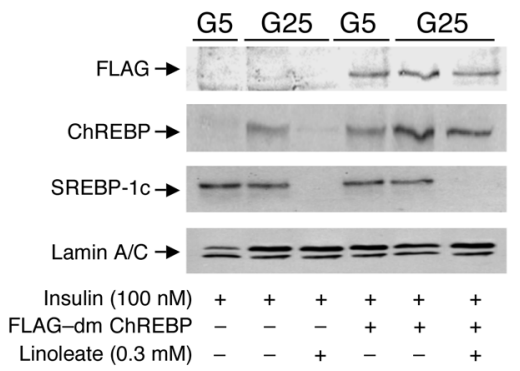

B

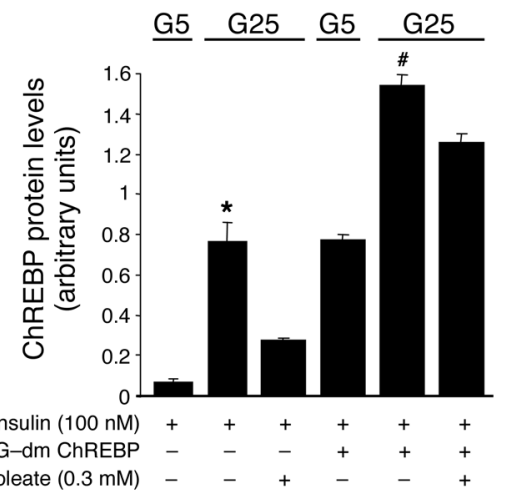

C

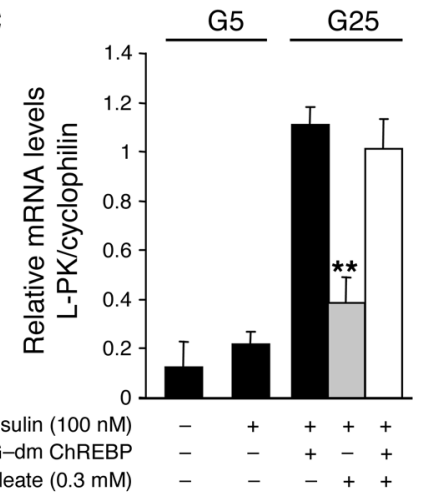

Linoleate $(0.3 \mathrm{mM})$

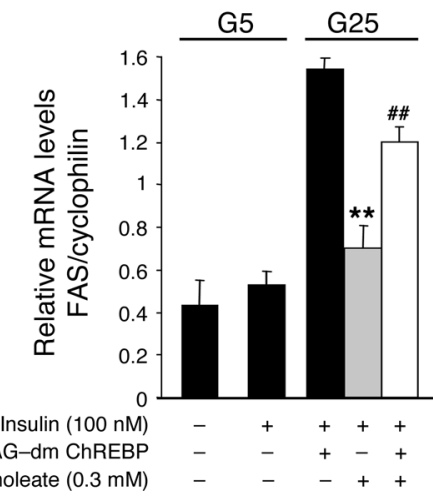

Figure 8

Overexpression of dm ChREBP in cultured hepatocytes counteracts the PUFA suppression of L-PK and FAS genes. After plating, hepatocytes were cultured for 24 hours in the presence of $5 \mathrm{mM}$ glucose. Hepatocytes overexpressing dm ChREBP were then incubated with 5 or $25 \mathrm{mM}$ glucose in the presence or not of $0.3 \mathrm{mM}$ of albumin-bound linoleate. (A) Nuclear forms of ChREBP and the mature form of SREBP-1c were measured. A representative Western blot of 3 independent cultures is shown. (B) Quantification of ChREBP levels under the indicated experimental conditions. Results are the mean \pm SEM of values obtained from 3 independent cultures. *Significantly different from $5 \mathrm{mM}$ glucose plus insulin $(P<0.05)$. "Significantly different from FLAG-dm ChREBP at $5 \mathrm{mM}$ glucose $(P<0.05)$. (C) After 24 hours, L-PK and FAS gene expression was measured by RTQ-PCR. Results are the mean \pm SEM of values obtained from 3 independent cultures. ${ }^{*}$ Significantly different from dm ChREBP in the presence of $25 \mathrm{mM}$ glucose plus insulin $(P<0.05)$. \#Significantly different from $25 \mathrm{mM}$ glucose plus insulin plus linoleate $(P<0.05)$.

fatty acids (34). In addition, the ability of PUFAs to directly activate AMPK remains controversial. While Suchankova and coworkers (24) reported that PUFAs modulate the AMPK phosphorylation status in rat liver, a recent study by Dobrzyn et al. (41) showed that PUFAs do not activate AMPK in mouse tissues in vivo. Similarly, under both our in vivo and in vitro experimental conditions, we did not observe any activation of AMPK in the presence of PUFAs. The discrepancy between our results and those of Suchankova et al. (24) could be due to differences in either diet composition or feeding conditions. Furthermore, the fact that studies have shown that the effect of PUFAs occurs without changing hepatocellular ATP levels $(42,43)$ suggests that PUFAs may act independently of AMPK. More important, our results obtained in AMPK $\alpha 1^{-/}$and AMPK $\alpha 2^{-/-}$mice clearly show that AMPK is not involved in the control of ChREBP nuclear translocation and in mediating the negative effect of PUFAs on both glycolytic and lipogenic gene expression. Indeed, in the absence of either the $\alpha 1$ or $\alpha 2$ subunit of AMPK, the ability of PUFAs to inhibit ChREBP translocation into the nucleus of hepatocytes is sustained. However, since the inhibitory effect of AMPK on glucose-stimu- lated gene expression is well established $(22,23)$, it should not be excluded that the AMPK-mediated phosphorylation of ChREBP on Ser568 could be important under specific physiological or physiopathological conditions.

The concomitant decrease in SREBP-1c and ChREBP gene and protein content suggests that this pair of transcription factors is involved in the inhibitory effect of PUFAs on glycolytic and lipogenic genes. The use of a dephosphorylated ChREBP (dm ChREBP), constitutively expressed in the nucleus regardless of the culture conditions, allowed us to demonstrate that PUFAs, by altering ChREBP nuclear translocation, prevent L-PK and FAS gene induction. The fact that FAS gene expression was not completely restored under $\mathrm{dm}$ ChREBP overexpression experiments confirmed that SREBP-1c, acting through its SRE-binding element, plays a determinant role for the regulation of FAS gene expression (44). Together our results are in agreement with chromatin immunoprecipitation experiments showing direct binding of SREBP-1c (45) and of ChREBP (19) on the promoter region of the FAS gene. Finally, the fact that for both FAS (46) and L-PK (14), glucose/insulin response elements overlap with putative PUFA response regions supports the hypothesis that carbohydrate and insulin stimulations and PUFA suppression are mediated by the coordinated action of ChREBP and SREBP-1c. The downregulation of ChREBP and SREBP-1c together provides a molecular explanation for the well-known shift in hepatic lipid metabolism from lipid synthesis and storage to oxidation associated with the ingestion of PUFAs.

In conclusion, our in vivo and in vitro results provide what we believe to be the first evidence that endogenous ChREBP is translocated from the cytosol to the nucleus under high glucose and insulin conditions and, in contrast, retained in the cytosol in the presence of PUFAs. The alteration of ChREBP translocation in the presence of PUFAs, which is independent of the action of AMPK, occurs through a specific inhibition of GK and G6PDH activities, key enzymes of glycolysis and of the pentose phosphate pathway, respectively (Figure 9). More important, the observation that the expression of a constitutively nuclear form of ChREBP in primary cultured hepatocytes not only overrides the negative effect of PUFAs on L-PK but also on the FAS gene demonstrates for the first time to our knowledge that ChREBP is a major determinant of the negative effect of PUFAs on both glycolytic and lipogenic genes (Figure 9).

\section{Methods}

Animals. Six- to 8-week-old male C57BL/6J mice were purchased from Elevage Janvier and adapted to the environment for 1 week prior to study. To determine the role of the AMPK in the regulation of ChREBP activity, 3- to 9-month-old control, AMPK $\alpha 1^{-/-}$(25), and AMPK $\alpha 2^{-/-}$(26) mice were used. All mice were housed in colony cages with a 12-hour light/12-hour dark cycle in a temperature-controlled environment. All animal studies were approved by the Direction départementale des services vétérinaires de Paris 


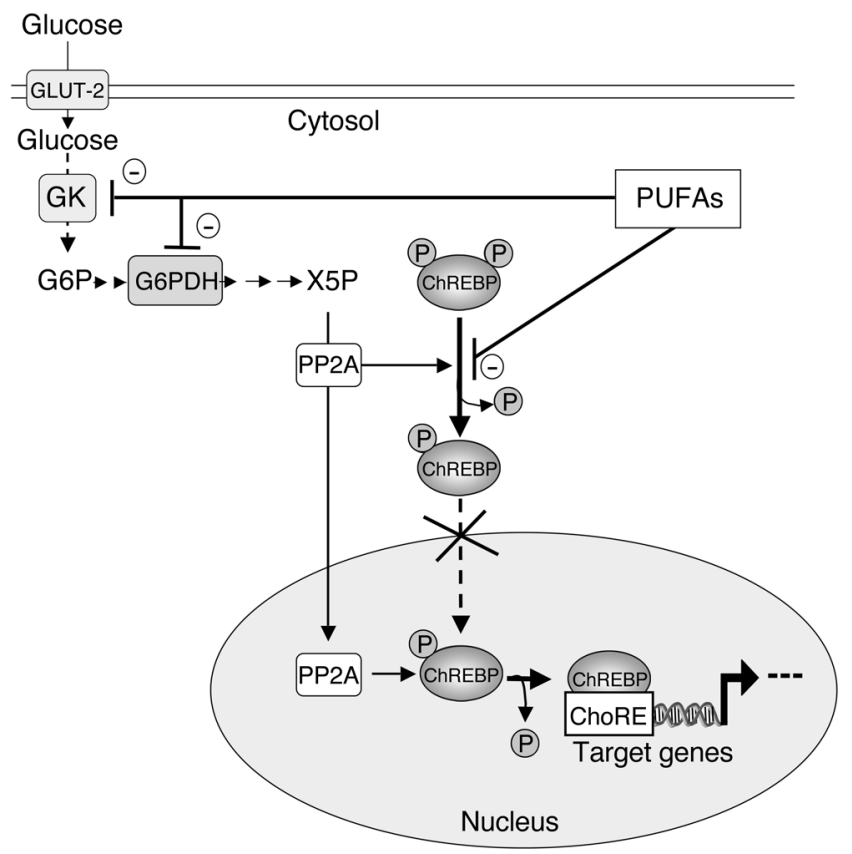

\section{Figure 9}

Inhibitory effect of PUFAs on ChREBP activation and translocation. Under basal conditions of low glucose and insulin concentrations, ChREBP is phosphorylated and localized in the cytosol of hepatocytes. Its nuclear translocation is rapidly induced under high glucose and insulin concentrations. The nuclear translocation of ChREBP is controlled by a mechanism of dephosphorylation and phosphorylation. While the dephosphorylation of serine residue 196 (Ser196) allows ChREBP translocation into the nucleus, the dephosphorylation of threonine residue 666 (Thr666) alleviates DNA-binding inhibition. Protein phosphatase 2A (PP2A), selectively activated by X5P, is believed to be responsible for both cytosolic and nuclear dephosphorylation of ChREBP. Then ChREBP binds its response element (ChoRE) to activate glycolytic and lipogenic gene expression. In the presence of PUFAs, ChREBP is retained in the cytosol through the specific inhibition of GK and G6PDH activities, key enzymes of glycolysis and of the pentose phosphate pathway, respectively.

(Paris, France). Mice had free access to water and regular diet (in terms of energy: $65 \%$ carbohydrate, $11 \%$ fat, $24 \%$ protein), unless otherwise specified.

Nutritional studies and in vivo insulin stimulation. To examine the role of PUFAs in ChREBP gene expression, mice were adapted for 5 days on a fatfree $\mathrm{HCHO}$ diet (high-carbohydrate diet [containing $75 \%$ of saccharose]; UAR). After a 5-day adaptation period, mice were fasted for 24 hours and then were randomly assigned to dietary treatments for 18 hours $(6$ mice per diet) that consisted of $\mathrm{HCHO}$ diet; $\mathrm{HCHO}$ diet supplemented with triolein [99\% grade, C18:1 (n-9); Sigma-Aldrich] (10 g triolein/100 g of HCHO diet) (HCHO-triolein); or HCHO diet supplemented with high-fat diet (hyperlipidic diet; UAR) (10 g high fat diet/100 g of HCHO diet) (HCHO-PUFA). The high-fat diet contains $45 \%$ of its PUFAs as linoleate [C18:2 (n-6)], $5 \%$ as EPA [C20:5 (n-3)], and 3.5\% as DHA [C22:6 (n-3)]. After an intraperitoneal anesthesia (a mix of ketamine/xylazine), livers were rapidly sampled, frozen in liquid nitrogen, and kept at $-80^{\circ} \mathrm{C}$ until RNA or protein extraction. For insulin signaling experiments, mice assigned to the described dietary treatments were anesthetized with a ketamine/xylazine mix and injected with $5 \mathrm{U}$ of regular human insulin (Actrapid Penfill; NovoNordisk Inc.) via the portal vein. Three minutes after injection of the insulin bolus, livers were removed and snap-frozen in liquid nitrogen. Immunoblot analysis of insulin signaling molecules was performed using liver homogenates prepared in a buffer as previously described (15). Rabbit polyclonal anti-Akt, anti-phospho-Akt (S473), anti-phospho-MAPK (ERK1 and ERK2), and anti-MAPK antibodies were purchased from Cell Signaling Technology. To study the phosphorylation state of AMPK in vivo, mice were fasted 24 hours before being fed HCHO or HCHO-PUFA diets for 3 hours. Upon refeeding, livers were removed and snap-frozen in liquid nitrogen.

Analytical procedures. The concentration of plasma insulin was determined using a rat insulin ELISA assay kit (Crystal Chem Inc.) according to the manufacturer's instructions using a mouse insulin standard. The binding reactions were modified to perform the assay on $10 \mu \mathrm{l}$ of plasma.

Primary cultures of hepatocytes. Hepatocytes were isolated from livers of fed mice by a modification of the collagenase method and seeded according to previously described procedures (15). For experiments using PUFAs, the medium was changed to a serum-free M199 medium containing $25 \mathrm{mM}$ glucose, $100 \mathrm{nM}$ dexamethasone, $100 \mathrm{nM}$ insulin, and various concentrations of albumin-bound stearate (C18), oleate [C18:1 (n-9)], linoleate [C18:2 (n-6)], EPA [C20:5 (n-3)], or DHA [C22:6 (n-3)] at a fatty acid/albumin ratio of 4:1 for 24 hours. The source of albumin for all studies was fatty acid-free BSA (Sigma-Aldrich). After 24 hours of culture in the presence of various concentrations of fatty acids, the culture medium was collected and analyzed for the activity of LDH. The leakage of LDH from hepatocytes in the culture medium was used to estimate the viability of hepatocytes after treatment with fatty acids and to test their toxicity. Briefly, $1 \mathrm{ml}$ of culture medium was used for spectrophotometric assay in $800 \mu \mathrm{l}$ of $50 \mathrm{mM}$ triethanolamine hydrochloride ( $\mathrm{pH} 7.6)$ containing $0.25 \mathrm{mg} / \mathrm{ml} \mathrm{NADH}$. After addition of pyruvate (100 $\mu \mathrm{M}$ final concentration), the linear decrease in absorbance at $340 \mathrm{~nm}$ was monitored, and the activity was determined. $\mathrm{LDH}$ activity is reported as micromoles of $\mathrm{NAD}^{+}$produced per minute per $10^{6}$ cells. For experiments using AICAR (Sigma-Aldrich), an activator of AMPK, hepatocytes were cultured in the presence of $25 \mathrm{mM}$ glucose, $100 \mathrm{nM}$ insulin, $100 \mathrm{nM}$ dexamethasone, and $500 \mu \mathrm{M}$ of AICAR.

Transfections experiments. For SREBP-1c overexpression experiments, hepatocytes were incubated for 120 minutes in $1 \mathrm{ml}$ of M199 medium with $1 \mathrm{PFU} /$ cell of recombinant adenovirus expressing SREBP-1c (Ad-SREBP-1c) (47), in the presence of $25 \mathrm{mM}$ glucose. The Ad-SREBP-1c expresses a truncated active nuclear form of this transcription factor (47). Then $25 \mathrm{mM}$ glucose M199 medium containing either albumin-bound $0.3 \mathrm{mM}$ linoleate at a fatty acid/albumin ratio of $4: 1$ or albumin alone was added, and cells were maintained in culture for 24 hours. For dm ChREBP overexpression experiments, hepatocytes were transfected using the polyethylenimine/adenofection method (15) with $2 \mu \mathrm{g}$ of pTZ18R expression vector containing the fulllength wild-type ChREBP- $\zeta$ isoform mutated on Ser196 and Thr666 (17) in $5 \mathrm{mM}$ glucose M199 medium, supplemented with $100 \mathrm{nM}$ dexamethasone and $100 \mathrm{nM}$ insulin. After transfection (5 hours), hepatocytes were cultured for 24 hours in M199 medium supplemented with $100 \mathrm{nM}$ dexamethasone and $100 \mathrm{nM}$ insulin. Then M199 medium at either 5 or $25 \mathrm{mM}$ glucose was added for 24 hours, in the presence of albumin-bound $0.3 \mathrm{mM}$ linoleate or albumin alone, $100 \mathrm{nM}$ dexamethasone, and $100 \mathrm{nM}$ insulin.

Determination of ChREBP subcellular localization. The full-length wild-type ChREBP- $\zeta$ isoform (17) was subcloned into the Invitrogen Corp. mammalian expression vector PEGFP-C1 encoding enhanced GFP (GFP-fused WT ChREBP). Two micrograms of GFP-fused WT ChREBP was transfected in cultured hepatocytes incubated in $5 \mathrm{mM}$ glucose M199 medium. After transfection (5 hours), hepatocytes were cultured for 24 hours in M199 medium. Then M199 medium at 5 or $25 \mathrm{mM}$ glucose was added for 24 hours, in the presence of either albumin-bound fatty acids or albumin alone, $100 \mathrm{nM}$ dexamethasone, and $100 \mathrm{nM}$ insulin. Subcellular localization of GFP-fused WT ChREBP was determined using a laser-scanning microscope. Fifty transfected hepatocytes from 3 independent cultures were scored to determine 
the localization of the GFP-fused WT ChREBP. For each condition, hepatocyte nuclei were specifically stained using DAPI.

Transcription and translation inhibition assays. Fatty acid regulation of glycolytic and lipogenic gene mRNA half-lives was evaluated by an $\alpha$-amanitin transcription inhibition assay. After cell attachment, hepatocytes were maintained in M199 medium containing $25 \mathrm{mM}$ glucose, $100 \mathrm{nM}$ dexamethasone, and $100 \mathrm{nM}$ insulin. Following a 48-hour incubation period to induce SREBP-1c and ChREBP gene expression, the medium was changed to one containing either albumin-bound $0.3 \mathrm{mM}$ linoleate, stearate, oleate, or albumin alone. After a 2-hour pretreatment, transcription was stopped by adding $\alpha$-amanitin ( $15 \mu \mathrm{M}$ final). The decay in mRNA levels encoding glycolytic and lipogenic enzymes was determined by realtime quantitative PCR (RTQ-PCR).

To examine the possibility that mRNA translation was needed for ChREBP mRNA to undergo decay, the half-life of ChREBP was determined in the presence of the translational inhibitor cycloheximide. ChREBP expression was first induced in cultured hepatocytes in the presence of glucose $25 \mathrm{mM}$ and $100 \mathrm{nM}$ of insulin. After 48 hours in culture, the cells were treated with cycloheximide ( $30 \mu \mathrm{M}$ final) for 2 hours and subsequently treated with $150 \mu \mathrm{M}$ albumin-bound linoleate or albumin alone for an additional 6 hours. The abundance of ChREBP was quantified using RTQPCR analysis, as described below.

Isolation of total $m R N A$ and analysis by RTQ-PCR. Total cellular RNAs were extracted using the RNeasy Kit (QIAGEN) according to the manufacturer's instructions. Total RNA (500 ng) was reverse transcribed as previously described (15). RTQ-PCR analysis for ChREBP, SREBP-1c, FAS, and L-PK gene expression was performed as previously described (15). The relative quantification for a given gene was corrected to the cyclophilin mRNA values.

Preparation of nuclear extracts and immunoblot analysis. Nuclear and cytoplasmic extracts were prepared from livers or cultured hepatocytes using the NE-PER nuclear and Cytoplasmic Extraction Reagent Kit (Pierce Biotechnology Inc.), according to the manufacturer's instructions. Proteins from nuclear extracts $(80 \mu \mathrm{g})$ and from the cytoplasmic fraction $(80 \mu \mathrm{g})$ were subjected to SDS-PAGE analysis on a $10 \%$ gel as previously described (15). SREBP-1 was detected with a mouse monoclonal antibody (SREBP-1 Ab-1; NeoMarkers; Interchim Inc.) raised against amino acids 301-407 of human SREBP-1 for 4 hours. Detection of signals was performed using the ECL Western Blotting Detection Kit (Pierce Biotechnology Inc.) with anti-mouse HRP-conjugated IgG (Pierce Biotechnology Inc.) as secondary antibody. ChREBP was detected with a goat polyclonal antibody (ChREBP P-13; Santa Cruz Biotechnology Inc.) for 4 hours. Detection of signals was performed with anti-goat HRP conjugated IgG (Pierce Biotechnology Inc.) as secondary antibody. Monoclonal mouse FLAG (clone M2; SigmaAldrich) antibody was used to detect the FLAG-dm ChREBP fusion protein (17). To detect the phosphorylation state of AMPK, liver samples or hepatocytes were homogenized in a buffer containing $50 \mathrm{mM}$ HEPES (pH 7.4), 50 mM NaF, 5 mM NaPPi, 1 mM EDTA, 1 mM EGTA, 10\% glycerol, $10 \%$ Triton X-100, 1 mM DTT, 1 mM PMSF, and a cocktail of protein inhibitors (aprotinin, leupeptin, pepstatin). A rabbit polyclonal phosphoAMPK $\alpha$ antibody based on the amino acid sequence surrounding Thr172 of the $\alpha$ subunit of human AMPK (Cell Signaling Technology) was used. A specific antibody for the $\alpha$ subunit of AMPK (Cell Signaling Technology) was used to confirm that the abundance of AMPK was similar among groups. Protein levels of the $\alpha 1$ and $\alpha 2$ AMPK subunits were determined using polyclonal antibodies generated in sheep as described previously (48) (antibodies were kindly donated by D.G. Hardie, University of Dundee, Dundee, United Kingdom). Monoclonal mouse $\beta$-actin (clone AC.74; Sigma-Aldrich) and polyclonal rabbit Lamin A/C (Cell Signaling Technology) antibodies were used as loading controls to normalize the signal obtained, respectively, for cytosolic and nuclear SREBP-1 and ChREBP. GK protein content was detected in liver homogenates (15) using a polyclonal antibody (used at a 1:1,000 dilution [ $\mathrm{vol} / \mathrm{vol}]$ ) raised against a recombinant glutathione-S-transferase-glucokinase fusion protein produced in sheep (49). Autoradiograms of Western blots were scanned and quantified using an image processor program (ChemiGenius ${ }^{2}$ imaging system; Syngene).

Measurement of G6P concentrations and GK and G6PDH activities. G6P concentrations and GK activity were measured in vivo and in cultured hepatocytes as previously described (15). For G6PDH activity measurements, liver samples or cultured hepatocytes were lysed in $1 \mathrm{ml}$ of homogenization buffer consisting of $50 \mathrm{mM}$ triethanolamine hydrochloride (pH 7.3), $100 \mathrm{mM} \mathrm{KCl}, 1 \mathrm{mM}$ dithiothreitol, 5\% glycerol, $1 \mathrm{mM}$ EDTA, $1 \mathrm{mM}$ EGTA, $1 \mathrm{mM}$ phenylmethylsulfonyl fluoride, $1 \mu \mathrm{g} / \mathrm{ml}$ pepstatin A, $1 \mu \mathrm{g} / \mathrm{ml}$ leupeptin. Homogenates were centrifuged at $10,000 \mathrm{~g}$ for $15 \mathrm{~min}$ utes at $4{ }^{\circ} \mathrm{C}$ after an incubation period of 15 minutes with $25 \%$ polyethylene glycol. G6PDH activity was measured in supernatants using an enzymatic method that measures the production of NADPH from $\mathrm{NADP}^{+}$in the presence of G6P. The assay buffer contained $100 \mathrm{mM}$ triethanolamine hydrochloride (pH 8), $100 \mathrm{mM} \mathrm{MgCl}_{2}, 1 \mathrm{mM}$ NADP, and $1 \mathrm{mM} \mathrm{G6P} \mathrm{(Sigma-}$ Aldrich). G6PDH activity is reported as milliunits/milligram protein, in which $1 \mathrm{mU}$ equals $1 \mathrm{nmol}$ of NADPH produced per minute.

Measurement of X5P. X5P concentrations were determined in cells extracts prepared from livers or from cultured hepatocytes by a modification of an enzymatic method (50). Briefly, X5P, from the neutralized supernatant previously used for G6P determination, was assayed spectrophotometrically in a reaction using transketolase in the presence of ribose 5-phosphate, thiamine pyrophosphate, $\mathrm{MgCl}_{2}$, sodium arsenate, coupled to glyceraldehyde 3-phosphate dehydrogenase in the presence of NAD. The increased absorbance at $340 \mathrm{~nm}$ after addition of $20 \mathrm{U} / \mathrm{ml}$ of transketolase was measured. Results are expressed as nanomoles of $\mathrm{X} 5 \mathrm{P} /$ milligram protein in vivo or as nanomoles of $\mathrm{X} 5 \mathrm{P} / 10^{6}$ cells in vitro.

Statistics. Results are reported as mean \pm SEM. The comparison of different groups was carried out using unpaired 2-tailed Student's $t$ test. Differences were considered statistically significant at $P<0.05$.

\section{Acknowledgments}

We would like to thank Howard C. Towle for providing wild-type and $\mathrm{dm}$ ChREBPs, Mark Magnuson for the gift of the GK antibody, and D. Grahame Hardie for the kind donation of AMPK $\alpha 1$ and AMPK $\alpha 2$ antibodies. We are grateful to Pierre-Damien Denechaud for making the GFP-fused ChREBP construct, Marie Daval for her advice on AMPK experiments, Mireille Cognet-Vasseur and Anaïs Perilhou for performing the insulin ELISA assays Anne-Françoise Burnol and Pascal Ferré for critical reading of the manuscript. We also thank the Vector Core of the University Hospital of Nantes supported by the Association Française contre les Myopathies (AFM) for providing the adenovirus-null vector. Mice used in this study were housed in an animal facility equipped with the help of the Région Ile de France. This work was supported by a grant from AlfediamTakeda and by 2 contracts (QLG1-CT-2001-01488, Ampdiamet, and LSHM-CT-2004-005272, Exgenesis) from the European Commission. R. Dentin is a recipient of a doctoral fellowship from the Ministère de l'Enseignement Supérieur et de la Recherche.

Received for publication April 4, 2005, and accepted in revised form July 19, 2005.

Address correspondence to: Catherine Postic, Institut Cochin, Département d'Endocrinologie, 24 rue du faubourg Saint Jacques, Paris 75014, France. Phone: 33-153-73-27-07; Fax: 33-153-73-27-03; E-mail: postic@cochin.inserm.fr. 
1. Jump, D.B., and Clarke, S.D. 1999. Regulation of gene expression by dietary fat. Annu. Rev. Nutr 19:63-90.

2. Liang, G., et al. 2002. Diminished hepatic response to fasting/refeeding and liver $\mathrm{X}$ receptor agonists in mice with selective deficiency of sterol regulatory element-binding protein-1c. J. Biol. Chem. 277:9520-9528.

3. Xu, J., Teran-Garcia, M., Park, J.H., Nakamura, M.T., and Clarke, S.D. 2001. Polyunsaturated fatty acids suppress hepatic sterol regulatory elementbinding protein-1 expression by accelerating transcript decay. J. Biol. Chem. 276:9800-9807.

4. Worgall, T.S., Sturley, S.L., Seo, T., Osborne, T.F., and Deckelbaum, R.J. 1998. Polyunsaturated fatty acids decrease expression of promoters with sterol regulatory elements by decreasing levels of mature sterol regulatory element-binding protein. J. Biol. Chem. 273:25537-25540.

5. Hannah, V.C., Ou, J., Luong, A., Goldstein, J.L., and Brown, M.S. 2001. Unsaturated fatty acids down-regulate srebp isoforms 1a and $1 \mathrm{c}$ by two mechanisms in HEK-293 cells. J. Biol. Chem. 276:4365-4372.

6. Mater, M.K., Thelen, A.P., Pan, D.A., and Jump, D.B. 1999. Sterol response element-binding protein $1 \mathrm{c}$ (SREBP1c) is involved in the polyunsaturated fatty acid suppression of hepatic S14 gene transcription. J. Biol. Chem. 274:32725-32732.

7. Yahagi, N., et al. 1999. A crucial role of sterol regulatory element-binding protein-1 in the regulation of lipogenic gene expression by polyunsaturated fatty acids. J. Biol. Chem. 274:35840-35844.

8. Stoeckman, A.K., and Towle, H.C. 2002. The role of SREBP-1c in nutritional regulation of lipogenic enzyme gene expression. J. Biol. Chem. 277:27029-27035.

9. Moriizumi, S., Gourdon, L., Lefrancois-Martinez, A.M., Kahn, A., and Raymondjean, M. 1998. Effect of different basic helix-loop-helix leucine zipper factors on the glucose response unit of the L-type pyruvate kinase gene. Gene Expr. 7:103-113.

10. Decaux, J.F., Antoine, B., and Kahn, A. 1989. Regulation of the expression of the L-type pyruvate kinase gene in adult rat hepatocytes in primary culture. J. Biol. Chem. 264:11584-11590.

11. Doiron, B., Cuif, M.H., Kahn, A., and Diaz-Guerra, M.J. 1994. Respective roles of glucose, fructose, and insulin in the regulation of the liver-specific pyruvate kinase gene promoter. J. Biol. Chem. 269:10213-10216.

12. Doiron, B., Cuif, M.-H., Chen, R., and Kahn, A. 1996. Transcriptional glucose signaling through the glucose response element is mediated by the pentose phosphate pathway. J. Biol. Chem. 271:5321-5324.

13. Diaz Guerra, M.J., et al. 1993. Functional characterization of the L-type pyruvate kinase gene glucose response complex. Mol. Cell. Biol. 12:7725-7733.

14. Liimatta, M., Towle, H.C., Clarke, S., and Jump, D.B. 1994. Dietary polyunsaturated fatty acids interfere with the insulin/glucose activation of L-type pyruvate kinase gene transcription. Mol. Endocrinol. 8:1147-1153.

15. Dentin, R., et al. 2004. Hepatic glucokinase is required for the synergistic action of ChREBP and SREBP-1c on glycolytic and lipogenic gene expression. J. Biol. Chem. 279:20314-20326.

16. Iizuka, K., Bruick, R.K., Liang, G., Horton, J.D., and Uyeda, K. 2004. Deficiency of carbohydrate response element-binding protein (ChREBP) reduces lipogenesis as well as glycolysis. Proc. Natl. Acad. Sci. U. S. A. 101:7281-7286.

17. Stoeckman, A.K., Ma, L., and Towle, H.C. 2004. Mlx is the functional heteromeric partner of the carbohydrate response element-binding protein in glucose regulation of lipogenic enzyme genes. J. Biol. Chem. 279:15662-15669.

18. Yamashita, H., et al. 2001. A glucose-responsive transcription factor that regulates carbohydrate metabolism in the liver. Proc. Natl. Acad. Sci. U. S. A. 98:9116-9121

19. Ishii, S., Iizuka, K., Miller, B.C., and Uyeda, K. 2004 Carbohydrate response element binding protein directly promotes lipogenic enzyme gene transcription. Proc. Natl. Acad. Sci. U. S. A. 101:15597-15602.

20. Kawaguchi, T., Takenoshita, M., Kabashima, T., and Uyeda, K. 2001. Glucose and cAMP regulate the L-type pyruvate kinase gene by phosphorylation/dephosphorylation of the carbohydrate response element binding protein. Proc. Natl. Acad. Sci.U.S. A. 98:13710-13715.

21. Kawaguchi, T., Osatomi, K., Yamashita, H., Kabashima, T., and Uyeda, K. 2002. Mechanism for fatty acid "sparing" effect on glucose-induced transcription: regulation of carbohydrate-responsive element-binding protein by AMP-activated protein kinase. J. Biol. Chem. 277:3829-3835.

22. Foretz, M., Carling, D., Guichard, C., Ferré, P., and Foufelle, F. 1998. AMP-activated protein kinase inhibits the glucose-activated expression of fatty acid synthase gene in rat hepatocytes. J. Biol. Chem. 273:14767-14771.

23. Leclerc, I., Kahn, A., and Doiron, B. 1998. The 5'AMP-activated protein kinase inhibits the transcriptional stimulation by glucose in liver cells, acting through the glucose response complex. FEBS Lett. 431:180-184.

24. Suchankova, G., et al. 2005. Dietary polyunsaturated fatty acids enhance hepatic AMP-activated protein kinase activity in rats. Biochem. Biophys. Res. Commun. 326:851-858

25. Jorgensen, S.B., et al. 2004. Knockout of the alpha2 but not alpha1 5'-AMP-activated protein kinase isoform abolishes 5-aminoimidazole-4-carboxamide-1-beta-4-ribofuranoside but not contraction-induced glucose uptake in skeletal muscle. J. Biol. Chem. 279:1070-1079.

26. Viollet, B., et al. 2003. The AMP-activated protein kinase $\alpha 2$ catalytic subunit controls wholebody insulin sensitivity. J. Clin. Invest. 111:91-98. doi:10.1172/JCI200316567.

27. Kabashima, T., Kawaguchi, T., Wadzinski, B.E., and Uyeda, K. 2003. Xylulose 5-phosphate mediates glucose-induced lipogenesis by xylulose 5 -phosphate-activated protein phosphatase in rat liver. Proc. Natl. Acad. Sci. U. S. A. 100:5107-5112.

28. Xu, J., Nakamura, M.T., Cho, H.P., and Clarke, S.D. 1999. Sterol regulatory element binding protein-1 expression is suppressed by dietary polyunsaturated fatty acids. A mechanism for the coordinate suppression of lipogenic genes by polyunsaturated fats. J. Biol. Chem. 274:23577-23583

29. Jump, D.B. 2004. Fatty acid regulation of gene transcription. Crit. Rev. Clin. Lab. Sci. 41:41-78.

30. He, Z., Jiang, T., Wang, Z., Levi, M., and Li, J. 2004. Modulation of carbohydrate response elementbinding protein gene expression in 3T3-L1 adipocytes and rat adipose tissue. Am. J. Physiol. Endocrinol. Metab. 287:E424-E430.

31. Clarke, S.D., Armstrong, M.K., and Jump, D.B. 1990. Dietary polyunsaturated fats uniquely suppress rat liver fatty acid synthase and S14 mRNA content. J. Nutr. 120:225-231.

32. Katsurada, A., et al. 1990. Effects of nutrients and hormones on transcriptional and post-transcriptional regulation of fatty acid synthase in rat liver. Eur. J. Biochem. 190:427-433.

33. Uyeda, K., Yamashita, H., and Kawaguchi, T. 2002. Carbohydrate responsive element-binding protein (ChREBP): a key regulator of glucose metabolism and fat storage. Biochem. Pharmacol. 63:2075-2080.

34. Jump, D.B., Clarke, S.D., Thelen, A., and Liimatta, M. 1994. Coordinate regulation of glycolytic and lipogenic gene expression by polyunsaturated fatty acids. J. Lipid Res. 35:1076-1084.

35. Stumpo, D.J., Prostko, C.R., and Kletzien, R.F. 1985. Ethanol-glucocorticoid regulation of hepatic glucose-6-phosphate dehydrogenase. Alcohol. 2:169-172.

36. Kletzien, R.F., Prostko, C.R., Stumpo, D.J., McClung, J.K., and Dreher, K.L. 1985. Molecular cloning of DNA sequences complementary to rat liver glucose-6-phosphate dehydrogenase mRNA. Nutritional regulation of mRNA levels. J. Biol. Chem 260:5621-5624.

37. Stabile, L.P., Hodge, D.L., Klautky, S.A., and Salati, L.M. 1996. Posttranscriptional regulation of glucose-6-phosphate dehydrogenase by dietary polyunsaturated fat. Arch. Biochem. Biophys. 332:269-279.

38. Stabile, L.P., Klautky, S.A., Minor, S.M., and Salati, L.M. 1998. Polyunsaturated fatty acids inhibit the expression of the glucose-6-phosphate dehydrogenase gene in primary rat hepatocytes by a nuclear posttranscriptional mechanism. J. Lipid Res. 39:1951-1963.

39. Tomlinson, J.E., Nakayama, R., and Holten, D. 1988. Repression of pentose phosphate pathway dehydrogenase synthesis and mRNA by dietary fat in rats. J. Nutr. 118:408-415.

40. Foufelle, F., Perdereau, D., Gouhot, B., Ferré, P., and Girard, J. 1992. Effect of diets rich in mediumchain and long-chain triglycerides on lipogenicenzyme gene expression in liver and adipose tissue of the weaned rat. Eur. J. Biochem. 208:381-387.

41. Dobrzyn, A., Dobrzyn, P., Miyazaki, M., and Ntambi, J.M. 2005. Polyunsaturated fatty acids do not activate AMP-activated protein kinase in mouse tissues. Biochem. Biophys. Res. Commun. 332:892-896.

42. Toussant, M.J., Wilson, M.D., and Clarke, S.D. 1981. Coordinate suppression of liver acetyl-CoA carboxylase and fatty acid synthetase by polyunsaturated fat. J. Nutr. 111:146-153.

43. Salati, L.M., and Clarke, S.D. 1986. Fatty acid inhibition of hormonal induction of acetyl-coenzyme A carboxylase in hepatocyte monolayers. Arch. Biochem. Biophys. 246:82-89.

44. Dentin, R., Girard, J., and Postic, C. 2005. Carbohydrate responsive element binding protein (ChREBP) and sterol regulatory element binding protein-1c (SREBP-1c): two key regulators of glucose metabolism and lipid synthesis in liver. Biochimie. 87:81-86.

45. Gosmain, Y., et al. 2005. Regulation of SREBP-1 expression and transcriptional action on HKII and FAS genes during fasting and refeeding in rat tissues. J. Lipid Res. 46:697-705.

46. Moon, Y.S., Latasa, M.J., Griffin, M.J., and Sul, H.S. 2002. Suppression of fatty acid synthase promoter by polyunsaturated fatty acids. J. Lipid Res. 43:691-698.

47. Foretz, M., et al. 1999. ADD1/SREBP-1c is required in the activation of hepatic lipogenic gene expression by glucose. Mol. Cell. Biol. 19:3760-3768.

48. Foretz, M., et al. 2005. Short-term overexpression of a constitutively active form of AMP-activated protein kinase in the liver leads to mild hypoglycemia and fatty liver. Diabetes. 54:1331-1339.

49. Liang, Y., et al. 1991. Effects of alternative RNA splicing on glucokinase isoform activities in liver, pancreatic islets, and pituitary. J. Biol. Chem. 266:6999-7007.

50. Mourrieras, F., et al. 1997. Induction of fatty acid synthase and S14 gene expression by glucose, xylitol and dihydroxyacetone in cultured rat hepatocytes is closely correlated with glucose 6-phosphate concentrations. Biochem. J. 326:345-349. 